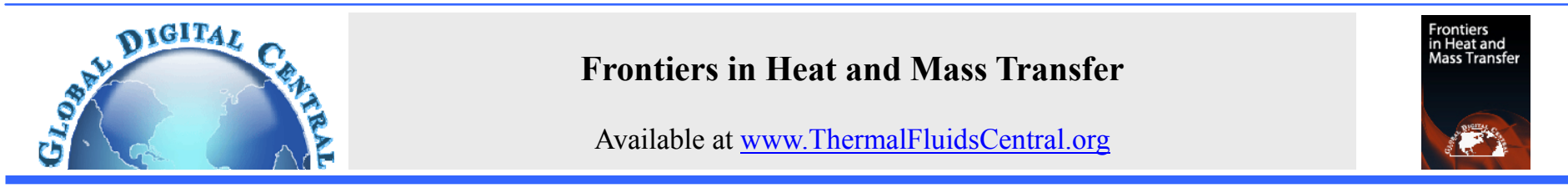

\title{
ON MODELING OF HEAT AND MASS TRANSFER AND OTHER TRANSPORT PHENOMENA IN FUEL CELLS
}

\author{
Bengt Sundén* and Jinliang Yuan \\ Department of Energy Sciences, Faculty of Engineering, \\ Lund University \\ Box 118, SE-22100 Lund, Sweden
}

\begin{abstract}
Depending on specific configuration and design, a variety of physical phenomena is present in fuel cells, e.g., multi-component gas flow, energy and mass transfer of chemical species in composite domains and sites. These physical phenomena are strongly affected by chemical/electrochemical reactions in nano-/micro-scale structured electrodes and electrolytes. Due to the electrochemical reactions, generation and consumption of chemical species together with electric current production take place at the active surfaces for all kinds of fuel cells. Furthermore, water management and twophase flow in proton exchange membrane fuel cells (PEMFCs) and internal reforming reactions of hydrocarbon fuels in solid oxide fuel cells (SOFCs) are strongly coupled with the electrochemical reactions and other transport processes to make the physical phenomena even more complicated. For modeling and analysis at the unit-cell and component level typically CFD-based approaches might be appropriate. On the fuel cell stack and system levels, methods like lumped parameter analysis and overall energy/mass balances are more suitable. This paper describes the various kinds of methods for modeling and analysis, and how these can be used as well as their applicability and limitations.

Keywords: Transport Phenomena, Chemical Reactions, Catalyst, fuel Cell, Model.
\end{abstract}

\section{INTRODUCTION}

During the last decades, a large amount of research activities have been carried out on fuel cells worldwide, with particular interest and focus on solid oxide fuel cell (SOFC) and proton exchange membrane fuel cell (PEMFC) systems. High performance, low cost and high reliability have been considered as the primary aspects and concerns for fuel cells to compete with well-developed fossil fuel power technology, such as power plants. Most of the work has focused on creating new materials and material processes for manufacturing of specific systems. It is believed that currently available fuel cell materials appear to be adequate for near-term markets with higher cost entry points, and industries are now focusing on fuel cell design and optimization for better performance, improved durability, cost reduction and better coldstart characteristics, and system studies including hybrid or integrated $\mathrm{SOFC} /$ gas turbine.

More attention then needs to be placed on detailed analysis of transport processes in fuel cell components and unit-cells, even at micro- and nano-scale levels. This is because the majority of the phenomena takes place in regions of the fuel cell that are inaccessible to experimental measurement. Furthermore, water-phase change/twophase flow in PEMFCs and internal reforming reactions of hydrocarbon fuels in SOFCs are strongly coupled with the electrochemical reactions and other transport processes to make the physical phenomena extremely complicated. On the other hand, extensive research work is also needed for fuel cell stacks for the purpose to efficiently deliver required power output at the load operating voltage, and to achieve proper water/thermal management for an integrated power plant including various units.

Scientific computing has been an extremely important tool for many industrial applications. There are well-developed computational fluid dynamics (CFD) codes, for example, that are widely used to optimize design or investigate the structures of a flow at a macroscopic scale. Similarly commercial codes are available for simulating integrated power system including several units. It is possible to use such simulation tools to make improvements to product design where physical design and testing is too expensive or not even possible. On the other hand, the microscale approaches (e.g., Density Functional Theory and Molecular Dynamics) and the mesoscale ones (e.g., Monte Carlo and Lattice-Boltzmann methods) take into account the effects of the multi-functional materials microscopic structures on the chargetransfer reactions at active sites, the surface chemistry and the gasphase chemistry based on elementary reaction kinetics (individual chemical reaction steps between intermediates).

This paper concerns the current status of fundamental models and analysis for fuel cells. It should be mentioned that this work is limited to PEMFCs and SOFCs at the macroscopic scales. However, there are various models for other fuel cells, e.g., molten carbonate fuel cell (MCFC) in Gundermann et al. (2008) and Brouwer et al. (2005), and for fuel cell material issues in Kreuer (2003). While a recent work by Anderssson M. et al. (2010) reviewed the various issues connecting to the microscopic modelling and integration with the macroscopic approaches.

Corresponding author. Email: bengt.sunden@energy.lth.se 


\section{PHYSICAL PHENOMENA AND MODELLING}

\subsection{Important Transport Phenomena and Reactions}

The major processes significant for the fuel cell characteristics are similar in SOFCs and PEMFCs. These processes are the species transport, electrochemical reactions, electronic and ionic transport, and heat transfer and temperature distribution. Figure 1 shows a unit-cell structure of fuel cells. It includes various components, such as fuel and oxidant ducts (or channels), electrolyte (polymer electrolyte membrane for PEMFCs), anode and cathode diffusion layers, catalyst layers in between them, as well as current inter-conductors.

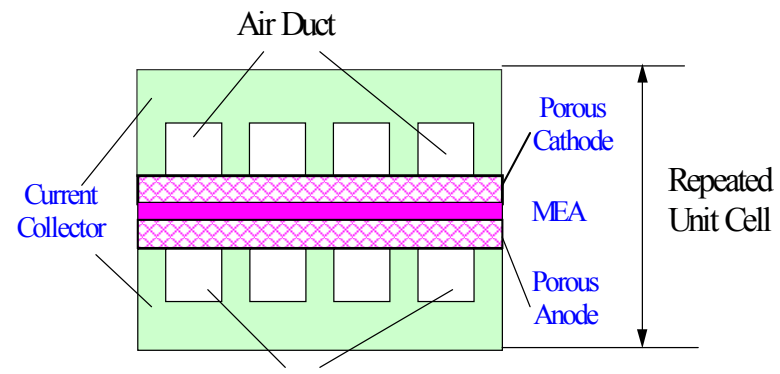

a)

Fuel Duct

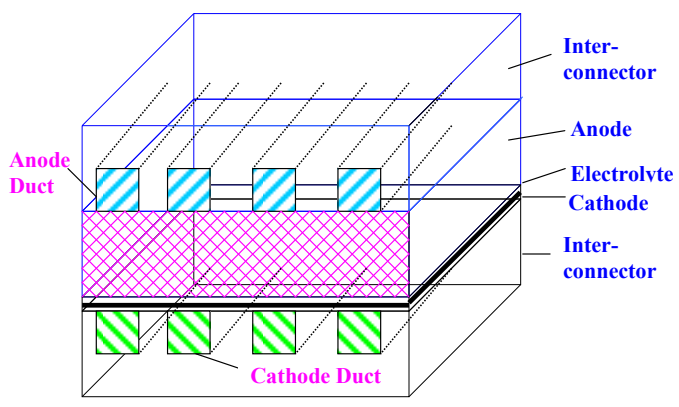

b)

Fig. 1 Schematic sketch of a unit cell for: $a$ ) PEMFC, and $b$ ) SOFC.

The major processes significant for the fuel cell characteristics are similar in SOFCs and PEMFCs. These processes are the species transport, electrochemical reactions, electronic and ionic transport, and heat transfer and temperature distribution. Figure 1 shows a unit-cell structure of fuel cells. It includes various components, such as fuel and oxidant ducts (or channels), electrolyte (polymer electrolyte membrane for PEMFCs), anode and cathode diffusion layers, catalyst layers in between them, as well as current inter-conductors.

In a fuel cell stack, the gas transport processes consist of the fuel and oxidant gas flows which are separated through the gas manifolds where no electrochemical reactions occur. The fuel and oxidant gases flow along cell ducts, where there is absorption of the reactants and injection of reactive products from/to the active sites. In the porous layers (electrodes), transport of the reactant gases occur towards triplephase boundary (TPB, where electrode, electrolyte and gas meet) between the electrolyte and the electrodes, and the exhaust gases are rejected to the cell ducts (or channels) through the open pores. The exhaust gases from each cell are discharged through the gas output manifolds.

In the anode duct, the fuel (e.g., $\left.\mathrm{H}_{2}\right)$ is supplied and air $\left(\mathrm{O}_{2}+\mathrm{N}_{2}\right)$ is introduced in the cathode duct. Reactants are transported by diffusion and/or convection to the TPB, where electrochemical reactions take place. Fuel cell ducts and manifolds should be designed/configured to have appropriate gas flow rates and flow uniformity to the reactive surface. An important concern is the net pressure loss, which should be as low as possible to reduce parasitic power needed to operate pumps or compressors. Consequently, a laminar flow regime is found in most of the fuel cells by employing small velocity and cross-sections in the manifolds and ducts (Kee et al. (2002)). The appropriate mass flow rate of reactants (fuels and oxidants) is determined by a number of factors, such as the requirement for the electrochemical reaction, proper thermal and water management, and internal fuel reforming reactions (in SOFCs) etc. In PEMFCs, the water management is critical to avoid the membrane dry out and cathode flooding. To deal with this concern, the oxidant flow rate may be increased to reduce the excess water generation.

Despite the big amount of experimental electrochemical data available, the mechanistic details of even the simple hydrogen oxidation reaction are still unclear, as claimed by Vogler, et al. (2009). It is often assumed that the electrochemical reactions take place close to the TPB. However there is some controversy regarding the actual pathway and nature of the elementary steps. More discussion can be found in, e.g., Vogler, et al. (2009). It is believed that an electrochemical oxidation reaction at the anode produces electrons that flow through the intercollector (bipolar plate, for PEMFC) or connector (for SOFC) to the external circuit, while the oxide ions (in SOFCs) or protons (in PEMFCs) pass through the electrolyte to the opposing electrode. The electrons return from the external circuit to participate in the electrochemical reaction at the cathode. In the electrochemical reaction process, part of the oxygen is consumed in the cathode duct, while the hydrogen is consumed in the anode duct. Heat and water $\left(\mathrm{H}_{2} \mathrm{O}\right)$ are the only by-products during the process. The water generated is injected into the anode duct further along the duct in SOFCs, while in PEMFCs, it enters into the cathode duct. The electrochemical reactions in SOFCs can be written as:

Cathode reaction: $\quad 1 / 2 \mathrm{O}_{2}+2 \mathrm{e}^{-} \rightarrow \mathrm{O}^{2-}$

Anode reaction: $\quad \mathrm{H}_{2}+\mathrm{O}^{2-} \rightarrow \mathrm{H}_{2} \mathrm{O}+2 \mathrm{e}^{-}$

and for PEMFCs:

Cathode reaction: $\quad 1 / 2 \mathrm{O}_{2}+2 \mathrm{e}^{-}+2 \mathrm{H}^{+} \rightarrow \mathrm{H}_{2} \mathrm{O}$

Anode reaction: $\quad \mathrm{H}_{2} \rightarrow 2 \mathrm{H}^{+}+2 \mathrm{e}^{-}$

The overall reaction is as follows:

$$
1 / 2 \mathrm{O}_{2}+\mathrm{H}_{2} \rightarrow \mathrm{H}_{2} \mathrm{O}
$$

The impact of the electrochemical reactions on the gas mass balance is represented by the absorption of reactants and generation of products at the TPB, in terms of mass flux rates $J\left(\mathrm{~kg} / \mathrm{m}^{2} \mathrm{~s}\right)$. The mass flux rate is related to local current density $I\left(\mathrm{~A} / \mathrm{m}^{2}\right)$ and reads as follows when pure hydrogen is used as fuel.

- $\quad$ SOFC anode

$$
\begin{aligned}
& J_{H_{2}}=-\frac{I}{2 F} M_{H_{2}} \\
& J_{H_{2} O}=\frac{I}{2 F} M_{H_{2} O}
\end{aligned}
$$

\section{- $\quad$ PEMFC anode}

$$
\begin{aligned}
& J_{H_{2}}=-\frac{I}{2 F} M_{H_{2}} \\
& J_{H_{2} O}=-\frac{\alpha}{F} I \bullet M_{H_{2} O}
\end{aligned}
$$


- $\quad$ SOFC cathode

$J_{O_{2}}=-\frac{I}{4 F} M_{O_{2}}$

- $\quad$ PEMFC cathode

$J_{O_{2}}=-\frac{I}{4 F} M_{O_{2}}$

$J_{\mathrm{H}_{2} \mathrm{O}}=\frac{1+2 \alpha}{2 \mathrm{~F}} I \bullet M_{\mathrm{H}_{2} \mathrm{O}}$

In the equations above, $\alpha$ is the net water transport coefficient in PEMFCs, which represents the net water transport through the membrane by electro-osmotic drag and back diffusion due to the water concentration difference, and hydraulic permeation due to the pressure difference between the two sides. Other symbols can be found in the nomenclature. It should be noted that the negative sign (-) in the above equations represents gas consumption, while plus $(+)$ means gas generation.

Due to the flow resistance in the fuel cells, the pressure drop $(\Delta P)$ along the ducts and in the manifolds can cause non-uniform flow distribution. Furthermore, as an effect the output of electrical energy will differ in terms of voltage potential and in some cases even gas recirculation occurs. At some severe conditions, the lack of gas in some ducts can cause the irreversible damage to the fuel cell components. The pressure drop depends on the duct and manifold structures, flow streams etc. However, the temperature is always non-uniform even when there is a constant mass flow rate in the ducts. This is caused by the heat transfer, phase change (in PEMFCs), and internal reforming reactions in SOFCs, which in turn cause fluctuation in the available $\Delta T$. Heat transfer occurs in the following manner:

- Between the cell component layers and the flowing air and fuel streams. This can be described in terms of heat transfer coefficients $h_{a}$ (for air duct), $h_{f}$ (for fuel duct) due to forced convective heat transfer with or without natural convection;

- Between the fuel and air streams across the interconnect layer in terms of the overall heat transfer coefficient, $U$, including convection and conduction.

- In solid structures in terms of heat conduction with different thermal conductivities, $k_{i}(i=$ electrolyte, electrodes and current inter-conductors).

For the electrolyte and porous layers, often referred to as the membrane electrode assembly (MEA) in PEMFCs, the overall principal energy balance can be written as:

$Q_{c}+h_{f} A_{f}\left(T_{e}-T_{f, a v}\right)+h_{a} A_{a}\left(T_{e}-T_{a, a v}\right)=Q_{s}$

where $Q_{c}$ is the heat conduction in the solid structure, $Q_{s}$ is the heat source to account for the electrochemical heat generation, ohmic heating caused by the electrical resistance due to the current flow; $h$ is the convective heat transfer coefficient; $T$ is the temperature. Equation (12) shows that the heat transfer coefficients in the reactant ducts are important. It should be noted that the coefficients for simple cases without the chemical reactions can be found in heat transfer textbooks, in terms of the Nusselt number $N u$. As discussed later in this paper, the convective heat transfer coefficients are significantly affected by the fuel cell chemical reaction related mass transfer (consumption/generation), the boundary conditions on the duct walls and the porous electrode characteristics (configuration, material/transport properties, etc). For the purpose to improve fuel cell modeling and analysis, it is essential to predict the local heat transfer coefficients for the anode/cathode ducts by considering the fuel cell design and configuration.

Electrodes for fuel cells are generally porous to ensure maximum active surfaces, and to allow the injection of the generated products to the ducts. The mass transfer is dominated by the gas diffusion and/or convection, as discussed later in this paper. This is ensured by the open pores of the electrodes, in terms of permeability and/or porosity. Another requirement of a porous electrode is to also have a good ionic conductivity, because the ions are transported via the solid matrix of the porous layer. In general, the electrodes should have a balanced performance and long-time stability. In PEMFCs, a catalyst material is frequently employed, such as platinum or platinum/ruthenium, whereas SOFCs utilize much cheaper catalyst materials such as nickel due to reduced activation polarization loss at higher temperature.

The electrolyte of fuel cells transports ions created by the electrochemical reaction at one electrode to the other. In PEMFCs the proton is transported through the electrolyte, while in SOFCs the oxygen ion is transferred. Reducing the electrolyte thickness and internal ohmic losses is a major requirement. On the other hand, the electrolyte should be impermeable to gases (fuel and oxidant) for the purpose of minimizing reactant crossover. The cell inter-connectors or collectors involve heat transfer by thermal conduction and current collection. Consequently, high electrical conductivity and thermal conductivity are the basic requirements. The materials having the following features like impermeability to reactants and chemical stability in oxidizing and reducing environments are commonly employed. In general, PEMFCs need more expensive materials, individually machined graphite or even gold-plated stainless steel materials.

It is well-known that the polarization curve, which represents the cell voltage behaviour against operating current density ( $V-I$ curve), is the standard measure of the performance for fuel cells, and it depends on both the operating conditions and the component design. The operating conditions include the temperature, partial pressures of fuel and oxidant and their utilization rates, and/or the water concentration in the components. On the other hand, the design parameters could be the porosity, tortuosity, thickness of the electrodes (concentration loss), thickness of the electrolyte (ohmic loss), and the electrode/electrolyte interface (activation loss).

There are certainly some specific aspects and physical phenomena which need to be carefully investigated for different kind of fuel cells. As an example, Nafion ${ }^{\circledR}$ membranes are often employed in the electrolytes in PEMFCs. These membranes possess high ion conductivity by selecting perfluorosulphonic acid copolymers with a short pendant group. However, the performance of the membranes, in terms of electrical conductivity, strongly depends on the water content. Factors influencing the water content in the electrolyte are generally two transport processes, i.e., water drag through the electrolyte membrane (a shell of $\mathrm{H}_{2} \mathrm{O}$ is transported via the electrolyte for every proton transported), and back diffusion of generated water from the cathode into the anode through the electrolyte. The first one is often referred to as electro-osmotic transport in the literature, and the latter one is due to the gradient of water content in the electrolyte. The effective electro-osmotic coefficient $\alpha$ is an important parameter to represent water transport between the anode and the cathode. It includes the effects of both electro-osmosis and water back diffusion.

Water management in the electrolyte is one of the major issues in PEMFCs. This is because during PEMFC operation anode gases can be dried out if the electro-osmosis transport rate is higher than that of back diffusion, which consequently causes the electrolyte membrane to become dehydrated and too resistive to conduct current. On the other hand, water is generated at the cathode active surface and transported to the cathode duct. Cathode flooding may occur when the water removal rate fails to reach its threshold transport/generation rate. Both dry-out and water flooding should be avoided, and various water management schemes have been proposed. More detailed discussions on these issues 
can be found in Singh et al. (1999), Okada et al. (1998), Kazim et al. (1999), Um et al. (2000), Voss et al. (1995) and Wang (2004). It should also be noted that condensation can occur in the cathode duct when local vapor saturation condition occurs in the duct. This case mainly happens at high current densities and low operating temperatures of the fuel cells.

SOFCs employ solid oxide material as electrolyte and are, therefore, more stable. There are no problems with water management, liquid water flooding in the cathodes or slow oxygen reduction kinetics in SOFCs. On the other hand there are other processes which only occur in SOFCs, such as internal reforming of fuels. Because of the high operating temperature, an SOFC can convert not only hydrogen into electricity, but can also reform hydrocarbon compounds into reactant fuels. For instance, methane can be converted to $\mathrm{H}_{2}$ and $\mathrm{CO}_{2}$ in a steam reforming process within the anode of SOFCs. This reforming process takes place at the surface and in a very thin layer of the anode porous nickel cermets (ceramic metal) (Lehnert et al. (2000)). It is often referred to as internal reforming reactions in the literature.

The methane reforming reaction in this case can be written as follows:

$$
\begin{array}{lc}
\mathrm{CH}_{4}+\mathrm{H}_{2} \mathrm{O} \rightarrow \mathrm{CO}+3 \mathrm{H}_{2} & \Delta H=206 \mathrm{~kJ} / \mathrm{mol} \\
\mathrm{CO}+\mathrm{H}_{2} \mathrm{O} \rightarrow \mathrm{CO}_{2}+\mathrm{H}_{2} & \Delta H=-41 \mathrm{~kJ} / \mathrm{mol}
\end{array}
$$

Equation (13b) is usually referred to as water gas shift reaction. The overall reforming reaction is:

$\mathrm{CH}_{4}+2 \mathrm{H}_{2} \mathrm{O} \rightarrow \mathrm{CO}_{2}+4 \mathrm{H}_{2}$

It should be mentioned that the above processes in Eq. (13) are net endothermic and the overall balance of the reaction requires external heat input. This heat can be supplied by the exothermic electrochemical reaction, as given in Eqs (1) and (2). Due to the fast reforming reaction compared to the electrochemical reaction, the endothermic steam reforming process may lead to local sub-cooling, and/or mechanical failure due to induced thermal stresses (Lehnert et al. (2000)).

It should be mentioned that, in fuel cells, the porous electrodes are multiphase materials (transport of reactants/products, electrons, and providing active sites for reactions in which the solid portion is either dispersed within a fluid medium or has a fluid network within. For the first case, the fluid medium occupies pores and the characteristic length is the diameter of the pores, while the particle size is the characteristic length if the solid fraction of the porous media is dispersed. In addition to pore diameter, or particle size, there are two more characteristics of flow paths in porous media, i.e., porosity and tortuosity. An effective electrode is the one that correctly balances each of the above transport processes and chemical reactions. The performance of individual electrodes is influenced by the properties and composition of the constituent material as well as the nano-/microstructure parameters. As an example, Ni-doped YSZ materials are typically employed as the porous electrodes in SOFCs. It is revealed that the pore or voids of diameter is less than $0.3 \mu \mathrm{m}$, and porosities around 0.3 , while the particle diameter is about $1 \mu \mathrm{m}$ for both spherical particles and sintered metal beads.

Fuel cell science and technology cut across multiple disciplines, including materials science, interfacial science, transport phenomena, electrochemistry and catalysis. It is often found that the endothermic and exothermic chemical reactions of the hydrocarbon fuels in SOFCs are strongly coupled by the electrochemical reactions on the active sites. There are various challenges in understanding the mechanisms of the transport processes involving the chemical reactions and their modeling.

\subsection{Fuel Cell Modeling and Analysis Approaches}

Modeling has already played an important role in fuel cell development because it facilitates a better understanding of parameters affecting the physical processes and the performance of fuel cell components and stacks. Such models are advantageous because experimental studies are costly and time consuming. Furthermore, experimentation is limited to designs, which already exist, thus does not facilitate innovative design. It is often impossible to measure critical parameters, such as temperature, pressure, potential gradients, and species concentration, due to the fuel cell reactive environment. However, there is no complete model for fuel cell stacks including all the phenomena together. Available models have generally been obtained for very restricted and idealized situations, and do not take into account other phenomena than the ones investigated. Nevertheless, increasing focus has produced significant attempts which will probably support further studies.

There are several issues which affect the choice of modeling strategies, and should be considered before selecting/developing a fuel cell modeling approach. The most important factors are the objectives and features of the model, such as steady/transient-state, theoretical/ semi-empirical, components/system study, lumped/multi-dimensional, accuracy/time/flexibility, validation/documentation and so on. The development of modeling and analysis tools is a cost and time consuming process. The level of user knowledge and available resources (such as personnel and computer facilities etc.) are also constraints to be included in the decision process.

In general, a model should be developed by considering the following features, such as testing, designing and optimizing. Given a predetermined configuration and operating conditions, the model should be able to provide a detailed description of the gas concentration, and the current, temperature distribution along the gas ducts. This information should be useful for calculating the overall power density, the efficiency and fuel utilization. The approach should be possible to extend to different cell configuration/geometry (i.e., planar, tubular and monolithic vs. electrolyte- and electrode-supported cell) and manifold arrays (co-, counter- and cross-flow). A set of optimal operating conditions should be possible to determine based on different trade-offs, such as higher voltage vs. lower current density, fuel utilization vs. maximum cell temperature etc.

Available fuel cell models can be categorized as analytical, semiempirical or mechanistic (often referred as theoretical). Usually many simplifying assumptions are applied in an analytical approach concerning variable profiles within the cell, for the purpose to develop an approximate analytical relationship between voltage and current density. This approach can in overall predict more parameters, such as water management requirement in PEMFCs, and be useful if quick calculations are required for fuel cell systems. It should be noted that the analytical models are only approximate for simple designs and do not give an accurate picture of transport processes occurring within the fuel cell components/cells.

On the other hand, based on experimental data specific to the applications and operating conditions, semi-empirical fuel cell models have also been developed during recent years. This approach combines theoretically derived differential or algebraic equations with empirically determined relationships, when the physical phenomena are difficult to model. This is also true when the theory governing the phenomena is not well understood.

Based on detailed electrochemical, fluid dynamics, species/current transport and heat transfer relationships, a theoretical fuel cell modeling approach usually employs the basic equations (differential and algebraic ones), such as the Stefan-Maxwell equation for gas-phase transport, and the Butler-Volmer equation for cell voltage (Haraldsson and Vipke (2004)). These equations are solved using some sort of computational methods for the tightly coupled electrochemical and transport processes. For proper water and thermal management, this 
approach includes not only the electrochemical reactions but also thermal- and fluid-dynamic equations. Multi-component species transport and heat transfer are important for providing a detailed picture of all physical processes in fuel cell components and stacks. The output of the modeling can provide details of the processes, such as fuel cell species distribution/flow pattern, current density/temperature distribution, voltage and pressure drop, etc. The theoretical models can be further divided into multi- or single-domain ones, based on the regions being treated (unified vs. multi) and the equations being solved (separately vs. simultaneously) (Cheddie and Munroe (2005)).

A multi-domain approach employs different sets of equations derived for each region of the cell, i.e., anode/cathode porous layers, electrolyte or membrane and catalyst layers, flow ducts of reactants etc, while the equations can be solved simultaneously and separately; On the other hand for a single-domain approach, all the regions of interest are combined into one domain, and conservation equations are defined for the domain, typically including gas flow regions (porous layers and gas flow ducts) or even the MEA. A set of generic convection-diffusion equations is formulated for the domain and the difference in each region is accounted for by source/sink terms, which allows for solution using well developed CFD codes (Cheddie and Munroe (2005)).

On the other hand, the microscale approaches (e.g., Density Functional Theory and Molecular Dynamics) and the mesoscale ones (e.g., Monte Carlo and Lattice Boltzmann Methods) are more related to theoretical knowledge compared to the global models. The detailed chemistry and surface reaction models are able to take into account the effects of the multi-functional materials microscopic structures on the charge-transfer reactions taking place at active sites, the surface chemistry and the gas-phase chemistry based on elementary reaction kinetics (individual chemical reaction steps between intermediates). Such reaction schemes usually consist of more than 10 surface-phase species and around 40 irreversible reactions. Implementation of such large reaction mechanisms in fuel cell design or conduction of parameter studies using CFD approach is a CPU demanding task. More discussion on the microscopic fuel cell modeling development and multi-scale integration technique can be found in a recent review work by Andersson M. et al., (2010).

In general, the above mentioned approaches have advantages and disadvantages. For instance, the theoretical modeling approach is flexible to applications and operating conditions, and may be appreciated when detailed studies are desired. However, development and implementation of this approach takes a longer time, and it is difficult to validate due to lack of detailed data in the open literature. At present, the most readily available data are simply the overall $V-I$ characteristics for a cell or stack. Although the semi-empirical and analytical approaches are already validated to some extent, they do not provide sufficient details. It should also be noted that the semiempirical models must be modified for each new application or operating conditions, and may not be suitable in some cases.

\section{COMPUTATIONAL FLUID DYNAMICS (CFD) MODELING APPROACH}

As mentioned above, fuel cell technology cuts across multiple disciplines, e.g., materials science, interfacial science, transport phenomena, electrochemistry, and catalysis. Fuel cell modelling and analysis then require a systematic framework to deal with the coupling of multidimensional transport processes with electrochemical kinetics and transport of charges (electrons and ions) for enabling comprehensive understanding and design. Various computational fluid dynamics (CFD) codes have been developed and applied for fuel cells particularly during the last few years, as outlined and discussed in recent review papers by Bhattacharyya and Rengaswamy (2009), and Kakaç et al. (2007).

\subsection{Governing Equations with Chemical Reactions and Phase Change}

The governing equations to be solved are conservation of mass, momentum, charge, thermal energy and species. These transport equations are coupled with electrochemical processes and other ones (such as chemical reactions of hydrocarbon fuels in SOFCs and water phase change in PEMFCs) through source/sink terms to describe the relevant processes in fuel cells. In the unified approach, all the governing differential equations can be arranged into a standard form (convection-diffusion-source), which can be discretized using the principles of CFD or solved using a commercial CFD software package.

The mass continuity equation or mass conservation equation is written as

$\nabla \cdot\left(\rho_{\text {eff }} \mathbf{V}\right)=S_{m}$

The source term $S_{m}$ in the above equation accounts for the mass balance caused by mass consumption or production from the chemical reaction (at catalyst layers or active surfaces), mass loss/gain through phase change as well as any other terms, which cannot fit the general format but must be accounted for.

It should be mentioned that the source terms can be expressed using the volumetric production/consumption rate of species due to the electrochemical reaction occurring at the TPB. For PEMFCs, it corresponds to the hydrogen and water consumption on the anode side, oxygen consumption and water generation on the cathode side, respectively. These are given by Dutta et al. (2000), and Shimpalee and Dutta (2000),

$$
\begin{gathered}
S_{m}=S_{\mathrm{H}_{2}}+S_{a, \mathrm{H}_{2} \mathrm{O}}=\left(-\frac{I}{2 F} M_{\mathrm{H}_{2}}-\frac{\alpha}{2 F} I \bullet M_{\mathrm{H}_{2} \mathrm{O}}\right) \frac{A_{\text {active }}}{V} \\
S_{m}=S_{\mathrm{O}_{2}}+S_{c, \mathrm{H}_{2} \mathrm{O}}=\left(-\frac{I}{4 F} M_{\mathrm{O}_{2}}+\frac{(1+2 \alpha) I}{2 F} M_{\mathrm{H}_{2} \mathrm{O}}\right) \frac{A_{\text {active }}}{V}
\end{gathered}
$$

$V$ here refers to the control volume at the active sites, $A_{\text {active }}$ the electrochemically active area per unit of electrode volume, $F(=96486.7$ $\mathrm{C} / \mathrm{mol}$ ) is Faraday's constant, $I$ the volumetric transfer current of the reactions by:

$$
I=i_{0}\left[\exp \left(\frac{\alpha_{a} F}{R T} \eta\right)-\exp \left(\frac{\alpha_{c} F}{R T} \eta\right)\right]
$$

in which, $i_{0}$ is the exchange current density, while $\alpha_{a}$ and $\alpha_{c}$ are the anodic and cathodic transfer coefficients, respectively. Equation (17), usually known as the Butler-Volmer equation and describing a large variety of electrode reactions, is further reduced to linear or Tafel expressions under certain conditions, e.g., facile and sluggish kinetics (Wang (2005)). It should be mentioned that the exchange current density $i_{0}$ for a reaction depends on the compositions and temperature at the reaction interface.

For a fuel $A$ with oxidant $B$, isothermal oxidation can be expressed by the following equation:

$a A+b B+\ldots \rightarrow x X+y Y+\ldots$

In an SOFC, the operating temperature is from $600{ }^{\circ} \mathrm{C}$ to $1000{ }^{\circ} \mathrm{C}$, and pressure of the gases is relatively not so high. Thus the gas species of reactants and products can be treated as ideal gases. When a gas is pure, ideal, and at $1 \mathrm{~atm}$, it is said to be in its standard state, expressed by a superscript ${ }^{0}$ after the symbol of interest. The theoretical electromotive force $(E M F)$ induced is the Nernst potential (Li et al. (2005)): 
$E=\frac{-\Delta G}{n_{e} F}=E^{0}+\frac{R T}{n_{e} F} \ln \frac{\left(P_{A} / P^{0}\right)^{a}\left(P_{B} / P^{0}\right)^{b} \ldots}{\left(P_{X} / P^{0}\right)^{x}\left(P_{Y} / P^{0}\right)^{y} \ldots}$

The first part of the right-hand side of the standard reaction is called the ideal potential, which is denoted by:

$E^{0}=\frac{-\Delta G^{0}}{n_{e} F}$

where $n_{e}$ is the number of electrons derived from a molecules of the fuel, when the fuel is oxidized in the reaction of Eq. (18), while $-\Delta G$ the Gibbs free energy change. For the case of operating with pure hydrogen fuel, the oxidation of hydrogen is the only electrochemical reaction in the fuel cell, and the Nernst potential will be:

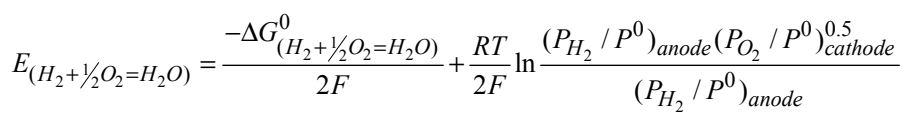

If all the pressures are given in bar, then $P^{0}=1$ bar, this equation simplifies to (Larminie and Dicks (2002)):

$E=E^{0}+\frac{R T}{2 F} \ln \left[\frac{P_{H_{2}} P_{O_{2}}^{1 / 2}}{P_{\mathrm{H}_{2} \mathrm{O}}}\right]$

It should be noted that the hydrogen can either be supplied in pure form or as part of a mixture. For the latter case, the hydrogen partial pressure should be used for the analysis. More discussion regarding operation with a hydrogen mixture and hydrocarbon fuels (such as methane) through the steam reforming and the water-gas shift reactions can be found in Li et al. (2005), and Larminie and Dicks (2002). If the hydrogen partial pressure changes from $P_{1}$ to $P_{2}$ bar, with $P_{O 2}$ and $P_{\mathrm{H} 2 \mathrm{O}}$ unchanged, the voltage will change by, see Larminie and Dicks (2002):

$\Delta V=\frac{R T}{2 F} \ln \left(P_{2}\right)-\frac{R T}{2 F} \ln \left(P_{1}\right)=\frac{R T}{2 F} \ln \left(\frac{P_{2}}{P_{1}}\right)$

It is a fact that, for a hydrogen fuel cell, the voltage is less than the theoretical value as shown in Eq. (22). In fact, there are three potential drops in a fuel cell that cause the actual output potential to be lower than the ideal $E M F$ of the electrochemical reaction. Whenever a current is drawn, the voltage drops and the actual cell voltage is given by Beale (2005):

$V_{\text {cell }}=E-\eta_{\text {ohm }}-\eta_{\text {act }}-\eta_{\text {trans }}$

where the terms $\eta_{o h m}, \eta_{a c t}$ and $\eta_{\text {mass }}$ are potential losses due to ohmic, activation, and mass transport or concentration resistances, respectively. These have often been referred to as overpotentials or polarizations in the electrochemistry and chemical engineering literature. The activation losses are caused by the slowness of the reaction taking place on the surface of the electrodes. A proportion of the voltage generated is lost in driving the chemical reaction that transfer the electrons to or from the electrode. The ohmic losses are due to the straightforward resistance to the flow of electrons through the material of the electrodes and various inter-connections, as well as the resistance to the flow of ions through the electrolyte. The mass transport losses result from the change in concentration of the reactants at the surfaces of the electrodes as the fuel is used, i.e., because of a failure to transport sufficient reactant to the electrode surface. It should be noted that fuel crossover can cause internal currents or an energy loss due to the waste of fuel passing through the electrolyte. As mentioned above, the electrolyte should only transport ions through the cell, however, a certain amount of fuel diffusion and electron flow (internal current) will always be possible. However, this effect is usually not very important (Larminie and Dicks (2002)).

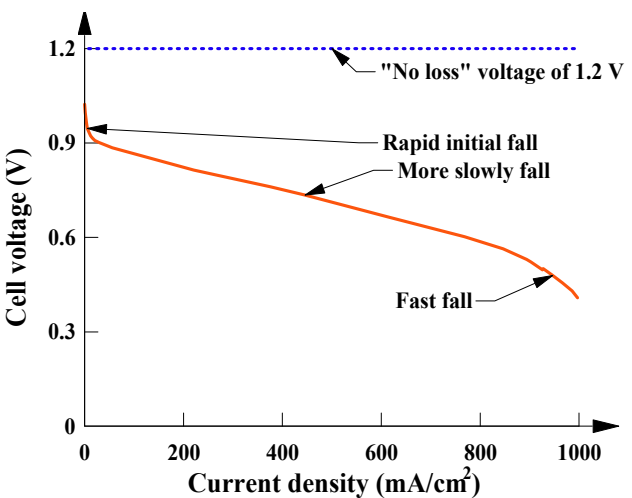

a)

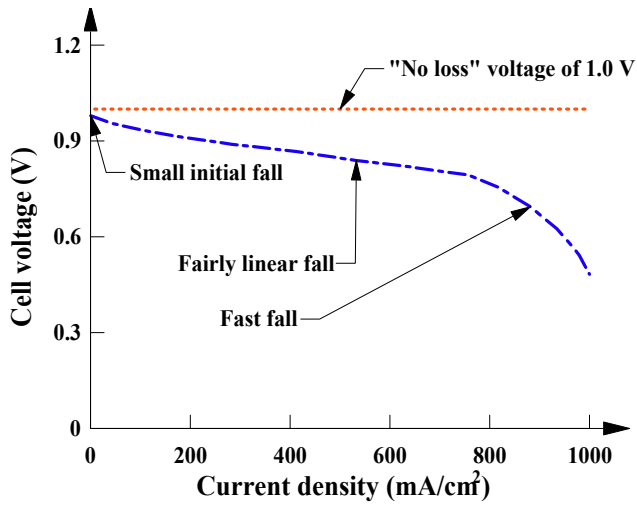

Fig. 2 The voltage for a typical: $a$ ) low temperature, and $b$ ) high temperature $\left(800^{\circ} \mathrm{C}\right)$, air pressure fuel cell (Larminie and Dicks

(2002)).

Figure $2 a$ shows the performance of a typical single cell operating at about $70{ }^{\circ} \mathrm{C}$, at normal air pressure. The theoretical value of the open circuit voltage of a hydrogen fuel cell is about $1.2 \mathrm{~V}$. It is found that the cell voltage is less than this due to the hydrogen crossover the electrolyte and/or internal current (Larminie and Dicks (2002)), as shown in Fig. $2 a$. It is also clear that there is a rapid initial fall in voltage associated with the activation losses, and the voltage then falls less rapidly and more linearly because the ohmic losses dominates in this region. There is sometimes a high current density at which the voltage falls rapidly if the mass transport losses appear, as shown in Fig. $2 a$. For the case with high operating temperature, the activation losses become small. It can be found from Fig. $2 b$ that the initial fall in voltage and the difference between the cell voltage and the "no loss" value usually becomes less. By comparing Figs. $2 a$ and $2 b$, it is found that the operating voltage is generally higher, although the reversible voltage is lower for the higher operating temperature.

The momentum equation reads

$\nabla \cdot\left(\rho_{\text {eff }} \mathbf{V V}\right)=-\nabla P+\nabla \cdot\left(\mu_{\text {eff }} \nabla \mathbf{V}\right)+S_{d i}$

The inclusion of the source term $S_{d i}$ allows Eq. (25) to be valid for both the porous layer and the flow duct

$S_{d i}=-\left(\mu_{e f f} \mathbf{V} / \beta\right)-\rho_{e f f} B V_{i} \mid \mathbf{v}$ 
The first term on the right hand side of the above equation accounts for the linear relationship between the pressure gradient and flow rate according to Darcy's law. The second term is the Forchheimer term which takes into account the inertial force effects, i.e., the nonlinear relationship between pressure drop and flow rate. In Eq. (26), $\beta$ is the porous layer permeability, and $\mathbf{V}$ represents the volume-averaged velocity vector of the species mixture. For example, the volumeaveraged velocity component $U$ in the $x$ direction is equal to $\varepsilon U_{p}$, where $\varepsilon$ is the porosity, $U_{p}$ the average pore velocity (or interstitial velocity). This source term accounts for the linear relationship between the pressure gradient and flow rate by the Darcy law. It should be noted that Eq. (25) is formulated to be generally valid for both the flow duct and the porous layer. The source term is zero in the flow duct, because the permeability $\beta$ is infinite. Equation (25) then reduces to the regular Navier-Stokes equation. For the porous layer, the source term, Eq. (26), is not zero, and the momentum Eq. (25) with the non-zero source term in Eq. (26) can be regarded as a generalized Darcy model.

The energy equation can be expressed as

$\nabla \cdot\left(\rho_{\text {eff }} c_{p, e f f} \mathbf{v} T\right)=\nabla \cdot\left(k_{\text {eff }} \nabla T-\sum_{i=1}^{n} \dot{\mathbf{m}}_{i} h_{i}\right)+S_{T}$

Equation (27) balances the convected energy, the heat conduction through the solid and the fuel gas mixture (heat conduction), the energy due to fuel gas species diffusion, and a source term $S_{T}$. In Eq. (27) $h_{i}$ is the partial enthalpy of the $i$ th species and is obtained from Beale (2005), and Haberman and Young (2004):

$h_{i}=h_{\text {form }, i}+\int_{T_{0}}^{T} c_{p i}(T) d T$

where $h_{\text {form }, i}$ is the specific enthalpy of formation of the $i$ th fuel species at $T=T_{0}=298.15 \mathrm{~K}$. For SOFCs involving internal reforming reactions, the heat source term $S_{T}$ in Eq. (27) is associated with the steam reforming and water-gas shift reactions,

$S_{T}=\sum_{i} R_{i} \Delta h_{\text {reaction, } i}$

where $R_{i}$ is the internal reforming reaction related mole fluxes, and $\Delta h_{\text {reaction, } i}$ is the reaction enthalpy. For PEMFC with water phase change (condensation/vaporization), the heat source term can be expressed as

$S_{T}=J w l \times h w l$

where $J_{w l}$ is the mass flux of liquid water by phase change, and $h_{w l}$ is the water latent heat.

The species conservation equations are formulated in a general form,

$\nabla \cdot\left(\rho_{\text {eff }} \mathbf{V} Y_{i}\right)=\nabla \dot{\mathbf{m}}_{i}+S_{s, i}$

where $Y_{i}$ is the mass fraction of the $i$ th fuel gas species, $\dot{\mathbf{m}}_{i}$ represents the mass diffusive flux of species in units of $\mathrm{kg} /\left(\mathrm{m}^{2} \mathrm{~s}\right)$, and $S_{s, i}$ the production/consumption rate of the $i$ th species. For an SOFC with internal reforming reaction of hydrocarbon fuels, the above equation is solved for $\mathrm{H}_{2}, \mathrm{CH}_{4}, \mathrm{CO}$ and $\mathrm{H}_{2} \mathrm{O}$, respectively, i.e., for $\mathrm{n}-1$ species where $\mathrm{n}$ is the total number of species involved in the fuel gas mixture. The last species $\left(\mathrm{CO}_{2}\right)$ can be solved because the sum of the mass fractions equals unity; while the above equation is solved for $\mathrm{O}_{2}, \mathrm{H}_{2} \mathrm{O}^{(\mathrm{v})}$ and $\mathrm{H}_{2} \mathrm{O}^{(1)}$ in the case of a PEMFC cathode, respectively. The concentration of the inert species, nitrogen, is determined from a summation of the mass fractions of the other species.

The charge conservation equation is solved for governing charge transport in the electronic phase. It involves the solution of the Poisson equations for the electric field over the entire region (the electrolyte, the electrodes and the current connectors), as in Beale (2005):

$\nabla \cdot\left(\sigma_{e f f} \nabla \phi\right)=S_{\phi}$

where $\sigma_{\text {eff }}$ is effective ionic/electric conductivity in the electrolyte or in the inter-connects/ collects. The source term $S_{\phi}$ is used to describe the transfer current between the electronic and electrolyte phases inside of each anode and cathode catalyst/active layers. Elsewhere in the gas flow duct, inter-connects/collects and electrolyte/membrane, $S_{\phi}$ is zero, i.e., the Poisson system reduces to the Laplacian equation. Discussion on various issues connected to the effective conductivity and the source terms can be found in Li et al. (2005) and Beale (2005) for various fuel cell designs.

It should be mentioned that a simple approach is often employed to treat the catalyst layer as an infinitely thin interface between the porous layer and the membrane in PEMFCs. In this case, the source term is applied as a boundary condition. This simplification is applicable since the catalyst is much thinner than the porous layer and the membrane (typical thickness of the catalyst layer is about 1/30 of the porous layer), as revealed by Meng and Wang (2004), and Yao et al. (2004).

\subsection{CFD Modeling Development}

A wide range of physical phenomena has been simulated and analyzed using CFD modeling approaches for fuel cell components/unit-cells and include transport processes, polarization effects (activation, ohmic and concentration overpotentials), effects of flow field geometry, thermal management, water management and $\mathrm{CO}$ poisoning/catalyst utilization in PEMFCs, and internal reforming reaction in SOFCs.

\subsubsection{Transport phenomena in fuel cell components}

In fuel cells, the gaseous reactant flows at both the cathode and anode are subject to fluid injection and suction along the porous interface to the electrolyte. Of vital interest is the effect that the duct/porous layer geometry and material parameters have on cell performance. For example, dimensionless pressure differences and convective heat transfer coefficients, represented by friction factors and Nusselt numbers, respectively, are calculated to account for the electrochemical reactions related mass transfer effects in fuel cell ducts (Yuan et al. (2005)).

To characterize the overall pressure difference between inlet and outlet, either a pressure coefficient $C_{p}$ or an apparent friction factor $f_{a p p}$ of the gas flow in a duct can be employed as

$C_{p}=\frac{\left(P_{i n}-P\right)}{\left(\rho U_{b u l k}^{2} / 2\right)}$

$4 f_{\text {app }}=\frac{D_{h}}{\left(\rho U_{b u l k}^{2} / 2\right)} \frac{d P}{d x}$

where $U_{\text {bulk }}$ is the mean velocity of the main flow, $D_{h}$ is the hydraulic diameter defined in the conventional manner, $d P / d x$ the pressure gradient along the main flow direction. The bulk velocity is calculated as:

$U_{b u l k}=\frac{\int U d A}{\int d A}$

and the hydraulic diameter is defined as: 
$D_{h}=\frac{4 A}{P^{*}}$

$A$ is the cross-sectional area and $P^{*}$ is the wetted perimeter. The apparent friction factor $f_{a p p}$ is employed in this study because it incorporates the combined effect of wall shear and the change in momentum flow rate due to the effects of mass generation and consumption by the electro-chemical reaction. The Nusselt number $N u_{w}$ can be defined as:

$N u=\frac{h D_{h}}{k}=\frac{q_{w} D_{h}}{k\left(T_{w}-T_{b u l k}\right)}$

where $N u$ is spanwise variable Nusselt numbers of the heated wall at location $x, q_{w}$ the wall heat flux, $T_{w}$ spanwise variable temperature of the heated wall.

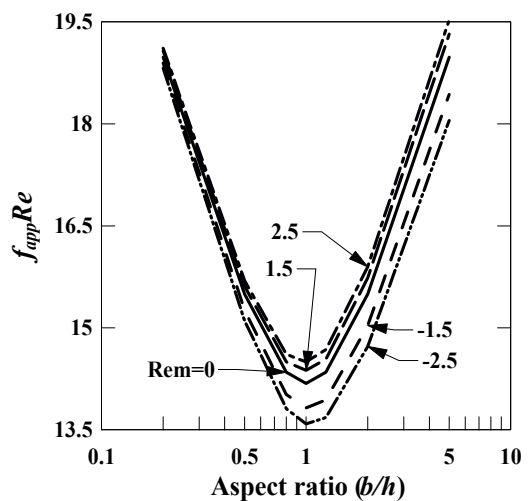

a)

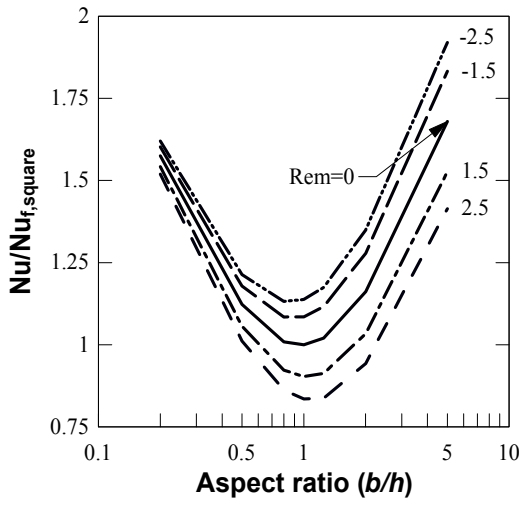

Fig. 3 Mass transfer $\left(R e_{m}\right)$ effects on the gas flow: $\left.a\right)$ the apparent friction factor; and $b$ ) Nusselt number in a rectangular fuel cell duct (Yuan et al. (2001)).

Mass transfer effects on the friction factor and Nusselt number are shown in Fig. 3 for a rectangular duct in fuel cells. For the case of mass injection (mass generation due to the electrochemical reactions) from the porous wall, additional mass is induced to the duct and thus the axial velocity increases. As clarified in Yuan et al. (2005), the $f_{a p p} R e$ is related to the pressure gradient as well as changes in the momentum flux in the main flow direction. As can be seen from Fig. $4 a, f_{a p p} R e$ always increases for mass injection $\left(R e_{m}>0\right)$, while it decreases for mass suction (mass consumption due to the electrochemical reactions, $\left.R e_{m}<0\right)$. On the other hand for heat transfer, the temperature of the fluid will increase due to the heat induced by mass injection, while a decrease appears for the case of mass suction. The $N u / N u_{f}$ is thus reduced by mass injection, which can be seen in Fig. $4 b$. A large aspect ratio of fuel cell ducts has a significant effect on both $f_{a p p} R e$ and $N u / N u_{f}$, while a small aspect ratio gives less effect. Both $f_{a p p} R e$ and
$N u / N u_{f}$ approach the values for the case without mass transfer $\left(R e_{m}=\right.$ 0 ), if the aspect ratio becomes about 0.1 . The figures show also that the $f_{a p p} R e$ and $N u / N u_{f}$ has a minimum when the aspect ratio is unity, i.e., a square duct (Yuan et al. (2001)).

Electrodes for fuel cells are generally porous to ensure maxium active surfaces, and to allow the injection of the generated products to the ducts. The importance of gas flow and heat transfer in the PEMFC porous layer and the effects on the transport processes in the flow duct are further evaluated using the CFD approach. Figure $4 a$ presents porous layer thickness effects on the main flow velocity profile (close to the exit) for a fixed value of the permeability $\left(\beta_{i}=2.0 \times 10^{-10}\right)$ (Yuan et al. (2001)). It is obvious that the fluid velocity in the porous layer decreases significantly by increasing the thickness of the porous layer. Figure $4 b$ corresponds to the case where the thickness of the porous region equals 20 percent of the duct height and the effect of permeability is shown. Clearly, in the porous layer the fluid flow rate is low, and it becomes significantly reduced when the permeability is low (e.g., $\beta_{i}=2.0 \times 10^{-11}$ ). However, the corresponding velocity profiles in the gas flow duct look very similar (see Fig. $4 b$ ). In Fig. $4 a$, it is noticed that the velocity gradient at the interface region between the porous layer and gas flow duct becomes sharper as the thickness ratio of the diffusion layer increases.

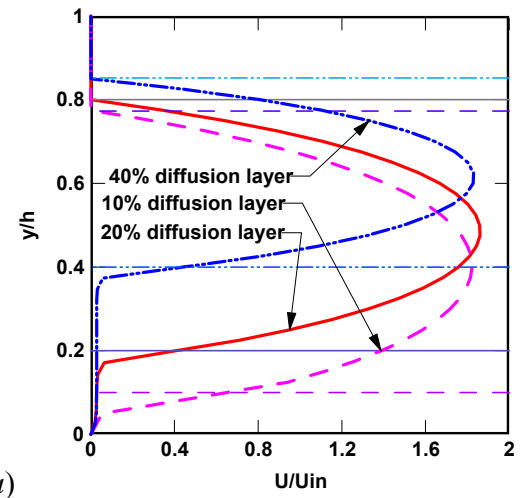

a)

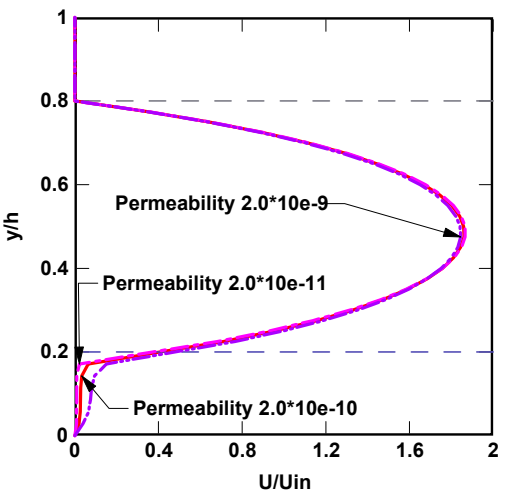

Fig. 4 Effects of: $a$ ) thickness; and $b$ ) permeability of porous layer on axial velocity profiles in a PEMFC cathode duct.

\subsubsection{Transport processes in cells}

Mass transport limitations or concentration overpotentials are caused if the reactants cannot be supplied fast enough for the required rate by the chemical reactions. This occurs at high current densities, particularly when large amounts of liquid water are produced at the PEMFC cathode. This is because liquid water has a two-fold effect, i.e., the reactants are diluted and the concentration near the catalyst sites is therefore reduced, and the effective gas porosity is reduced due to occupation of liquid water in the porous cathode. A one-dimensional model was developed in Baschuk and Li (2000) to account for cathode mass limitation effects by allowing variable degrees of flooding at the 
cathode catalyst layer/backing region. The model predicted that increasing the cell pressure lowers the limiting current density, while increasing the temperature has opposite effect, i.e., increase of the limiting current density.

A 2-D model developed in Um et al. (2000) studied the effects of hydrogen dilution along a PEMFC anode gas duct for the directions perpendicular to the MEA cross-section and the flow stream. The simulated results show that mass transport limitations take place on the anode side, particularly at high current densities and when reformed fuel other than pure hydrogen is employed. This is so because hydrogen is extracted from the flow ducts at a much fast rate for the case of high current densities, and the partial pressure of the hydrogen is already lowered by the presence of carbon dioxide in the reformed fuel supply. In these cases, the partial pressure of the hydrogen may be too low and it may not be able to transport (dominated by diffusion, as discussed later in this chapter) to the anode catalyst layer fast enough. It is also revealed that such characteristics cannot be studied using onedimensional models.

There are 3-D models available in the literature to parametrically study the fuel cell performance. For example, Wang et al. (2001) developed a parametric model to study the effects of temperature, humidity and pressure on the PEMFC performance, and the modeling results show that the cell performance improves with increasing temperature if the inlet gases are fully humidified. Generally the model overestimates the cell current density compared to experimental one if mass transfer effects were not taken into account. $\mathrm{CO}$ poisoning of the catalyst and hydrogen dilution due to the inert gases were evaluated in another 3-D model (Zhou and Liu (2004)). Due to preferential adsorption at the catalyst layers, the $\mathrm{CO}$ is depleted at a faster rate and the hydrogen concentration then increases in the main flow direction. It was revealed that the optimum porosity of the porous layer (anode) is much lower for a fuel cell using reformate instead of using pure hydrogen.

To reduce the cost and increase the expected life time, many efforts have been performed to reduce the SOFC operating temperatures to intermediate range (between $600-800^{\circ} \mathrm{C}$, ITSOFC hereafter). Two technical routes for ITSOFCs have emerged, i.e., thin film technology is employed for the first case with conventional yttriastabilized zirconia (YSZ) for the electrolyte. When the working temperature is reduced to around $700^{\circ} \mathrm{C}$, the specific ionic conductivity is about $0.01 \mathrm{~S} / \mathrm{cm}$, and then the maximum thickness allowed for conventional YSZ electrolyte is $8-15 \mu \mathrm{m}$ (Yuan et al. (2003)). The electrode-supported (e.g., anode-supported) configuration is usually employed for this thin electrolyte structure. The second case employs new materials with very high ionic conductivity $(\sigma=1.0 \mathrm{~S} / \mathrm{cm}$ at 700 ${ }^{\circ} \mathrm{C}$ ). If a thick layer electrolyte (around $500 \mu \mathrm{m}$ thick) is adopted, the contribution to the total area specific resistance is about $0.05 \Omega \mathrm{cm}^{2}$, which is still lower than that of the conventional high temperature SOFCs (HTSOFCs hereafter) (Yuan et al. (2003)).

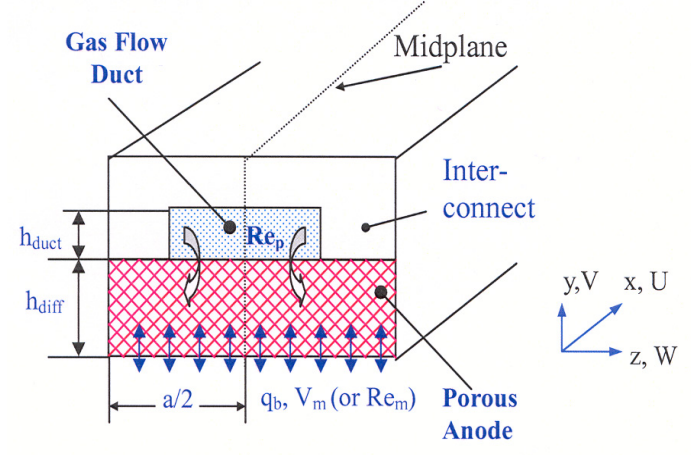

Fig. 5 Schematic drawing of an ITSOFC composite anode.
For anode-supported planar SOFCs (or ITSOFC), the thickness and width of the porous layer (anode) is larger than that of the flow duct. The transport rate of fuel gases to active sites for reactions is controlled by various parameters, such as porous microstructure (e.g., pore size, permeability, volume percent porosity), pressure gradient between the flow duct and porous layer, gas composition and inlet conditions (Yuan et al. (2003)). A three-dimensional CFD model applying the unified approach is developed and employed for a composite anode consisting of a thick porous anode layer, the gas flow duct and solid current inter-connector (as shown in Fig. 5). The porous anode layer is assumed to be homogeneous and characterized by effective parameters, such as porosity, permeability and thermal conductivity, and the fluid in the porous layer is in local thermal equilibrium with the solid matrix. A chemical reaction occurs at the porous surface in contact with the electrolyte (bottom surface in Fig. 5). A constant flow rate $U=U_{\text {in }}$ with a mass fraction of the mixed fuel $\left(\mathrm{H}_{2} / \mathrm{H}_{2} \mathrm{O}=80 / 20\right)$ is specified at the inlet of the gas flow duct, while $U=0$ is presented at the inlet for the inter-connector and porous anode layer. The typical geometry and parameters employed are shown in the following table:

Table 1: Parameters implemented as the base case in an ITSOFC anode (Yuan et al. (2005))

\begin{tabular}{|l|l|l|l|}
\hline length of the duct $L$ & $20 \mathrm{~mm}$ & permeability $\beta$ & $2 \times 10^{-10} \mathrm{~m}^{2}$ \\
\hline porous layer $a$ & $2 \mathrm{~mm}$ & inlet temperature $T_{\text {in }}$ & $700{ }^{\circ} \mathrm{C}$ \\
\hline porous thickness $h_{p}$ & $2 \mathrm{~mm}$ & porosity $\varepsilon$ & 0.5 \\
\hline $\begin{array}{l}\text { width of the } \\
\text { flowing duct } b\end{array}$ & $1 \mathrm{~mm}$ & $\begin{array}{l}\text { mass fraction of } \mathrm{H}_{2} \\
\text { /water vapor }\end{array}$ & $0.8 / 0.2$ \\
\hline $\begin{array}{l}\text { height of the } \\
\text { flowing duct } h_{d}\end{array}$ & $1 \mathrm{~mm}$ & $\begin{array}{l}\text { diffusion coefficient } \\
D_{H 2}\end{array}$ & $3 \times 10^{-4} \mathrm{~m}^{2} / \mathrm{s}$ \\
\hline
\end{tabular}

$\mathrm{H}_{2}$ concentration profile along the main flow direction is shown in Fig. 6. It is found that the $\mathrm{H}_{2}$ concentration decreases continuously along the main flow direction in the porous layer and the flow duct. This is due to the consumption of $\mathrm{H}_{2}$ during the electrochemical reaction. Moreover, the gradients of the $\mathrm{H}_{2}$ concentration in the direction normal to the active surface (the bottom surface in Fig. 6) are larger close to the interface areas of both the porous layer and flow duct compared to those close to the reaction sites.

It is clear that the fuel gas species is transported to the active sites for the reaction by both convection and diffusion in the porous layer. However, the species transport rate in the porous layer is smaller than that in the flow duct, which can be verified by a flat mass fraction profile close to the interface areas in the porous layer. It is also clear from the figures that the $\mathrm{H}_{2}$ concentration is large in the porous layer in the entrance region, due to the significant mass permeation across the interface from the flow duct, as discussed above.

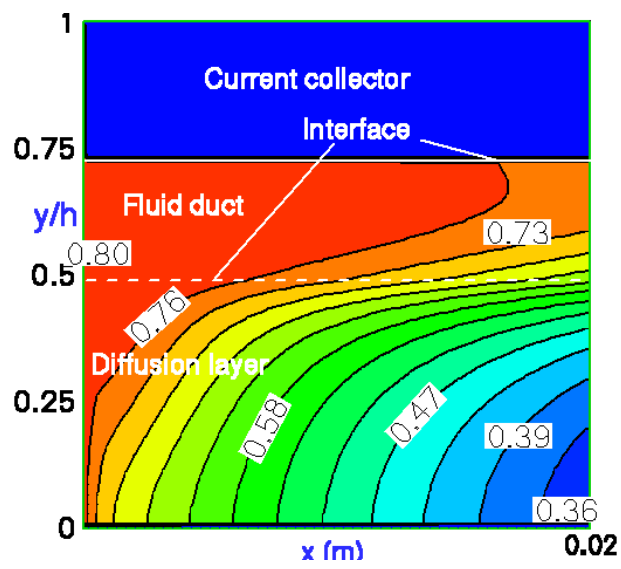

Fig. $6 \mathrm{H}_{2}$ mass concentration distribution along the main flow direction of an ITSOFC anode. 
Hydrogen mass fraction profiles are further plotted in Fig. 7 for the cross section at the stations of the half-length from the inlet and the exit of the duct. It is found that, in a cross section, the hydrogen mass fraction has minimum values close to the bottom active surface, which is caused by the electrochemical reaction mentioned above. Almost uniformly distributed mass concentration is found in both the flow duct and the porous layer. However, a larger value has been predicted in the porous layer close to the side wall.

The performance of the ITSOFC anode is also analysed using the vertical component of the total hydrogen mass flux vector at the active site (bottom surface), which is proportional to the local current density produced. It is given by

$\left(J_{H_{2}, y}\right)_{b}=\left(\rho_{\text {eff }} Y_{H_{2}} V-\rho_{\text {eff }} D_{H_{2}, e f f} \frac{\partial Y_{H_{2}}}{\partial y}\right)_{b}$

It should be noted that the first part on the right hand side represents the convection effects, while the second part is the contribution by the diffusion.

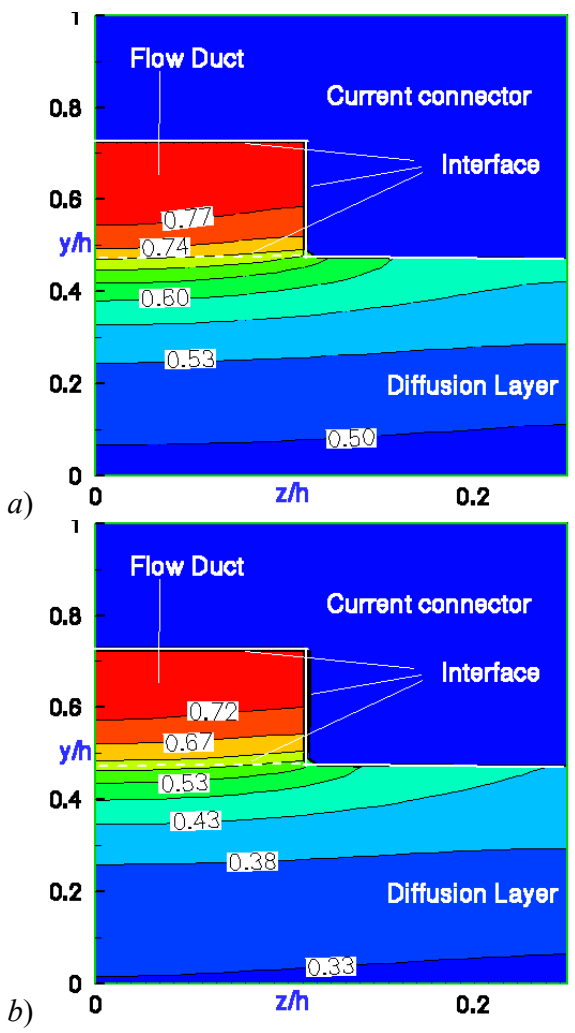

Fig. 7 Cross-sectional hydrogen mass concentration distribution at: $a$ ) $1 / 2$ length from the inlet; $b$ ) the exit of ITSOFC anode.

Figure 8 shows a comparison of the hydrogen mass fluxes by convection, diffusion and the total value. It can be seen that the convection mass flux has a large negative value (i.e., fuel species transport is to the reaction sites) at the inlet region. Due to the decreasing pressure difference along the duct, this convection becomes weaker. On the other hand, water generation caused by the electrochemical reaction at the active sites, together with back permeation clarified in Yuan et al. (2005), contributes to species flowing back to the flow duct. This is confirmed by a small positive value of the convection flux. It is also clear that the hydrogen diffusion flux maintains an almost constant value. By comparing the absolute values of convection and diffusion fluxes, it is found that the convection is stronger in the entrance region; however, the diffusion dominates the species transport further downstreams. The position, where this change occurs, is about $1 / 6$ length from the inlet for this specific case. Consequently the total flux from Eq. (37) is controlled by the convection in the entrance region, and dominated by the diffusion for the rest of the duct, see Fig. 8 .

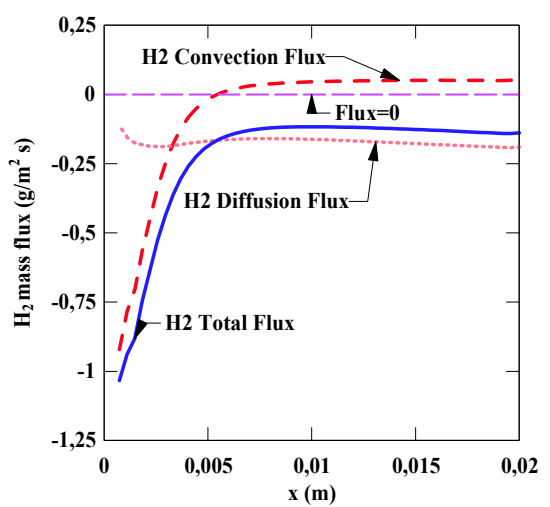

Fig. 8 Various contributions to hydrogen flux at the bottom wall of ITSOFC anode.

\subsubsection{Thermal management and heat transfer modeling}

As mentioned above, the electrochemical reactions occurring in fuel cells are exothermic, i.e., the heat is generated together with the contribution of the ohmic resistance. Heat removal and proper thermal management are critical design and operating issues in fuel cells. For instance, excessive heat generation may result in dehydration of membrane, and in such case, decreased conductivities and thermal stresses are expected, even mechanical failure of fuel cell components (Cheddie and Munroe (2005)). Non-isothermal models using CFD approach can be found in the literature to analyze the heat transfer and effects on the PEM cell performance, such as (Berning and Djilali (2003)). It is revealed that a temperature difference of 2-3 K exists within the cell, and the same magnitude of temperature variation is observed as well in Yan et al. (29).

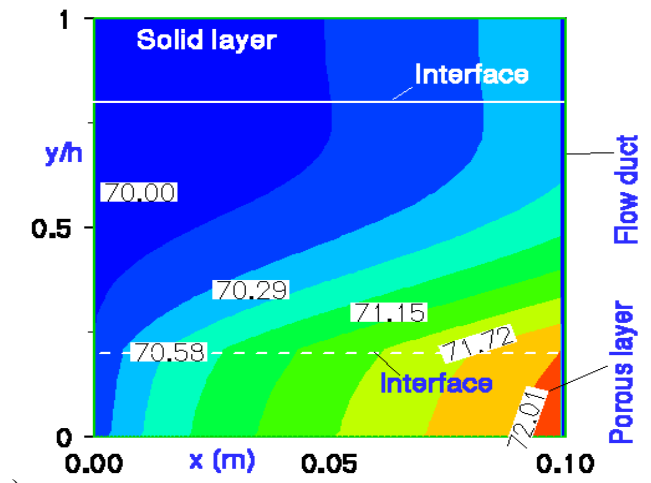

a)

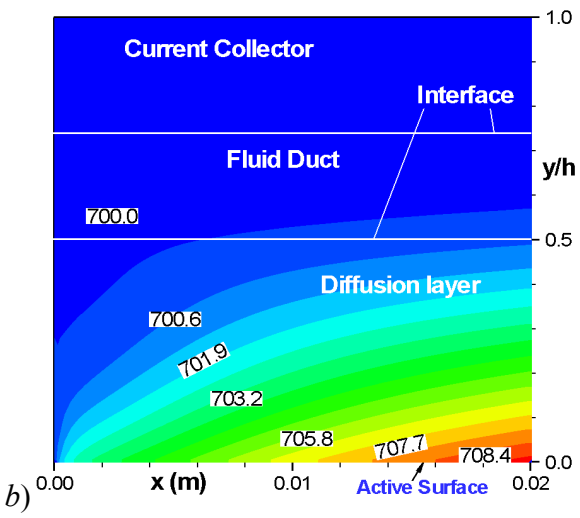

Fig. 9 Contours of temperature $T$ along the main flow direction of: $a$ ) a PEMFC cathode duct, $b$ ) an ITSOFC anode duct. 
Figure 9 shows that the temperature increases along the main flow direction of PEMFC composite cathode and SOFC anode, respectively, which include the gas flow duct, porous layer and solid currentcollector. The variation in temperature distribution can be observed in the vertical direction with a slightly larger value close to the bottom surface. These effects are created by the heat generation due to the reaction close to the active surface, and the latent heat release by water condensation in the two-phase region (Fig. 9a for PEMFC). It is worthwhile to note that the temperature is non-uniformly distributed. By considering the local temperature distribution, the effects on the PEMFC saturation pressure can be found, as discussed later in this chapter.

In SOFCs, thermal radiation may play an important role because of the high operating temperature. Radiation heat transfer may be important within the gas flow duct, within the electrolyte-electrode assembly, and when thermal insulation layers are employed. It is believed that the thermal radiation is a mechanism by which it may be possible to actually control cell/stack temperature and temperature gradients, by manipulating the optical properties of the electrode, electrolyte, and even interconnect materials or employing radiation shields (Beale (2005)). In SOFC unit cells, the radiation heat transfer involves radiative transfer in participating media (such as electrodes, electrolyte and participating gases) and surface-to-surface radiation. While for SOFC stacks, it is required to maintain uniform temperature profiles and not allow the cells near the edges to operate at lower temperatures than cells in the interior of the stacks. Thus the proper design of high temperature thermal insulation for SOFC stacks involves an analysis of thermal radiation in the insulation materials, and further to the environment (Damm and Fedorov (2005)).

The general radiation heat transfer problem in a participating medium involves heat transfer which can be mathematically described by an integro-differential equation, often referred to as the radiative transfer equation (RTE hereafter).

$\frac{d i}{d s}=-\left(a+\sigma_{s}\right) i+a \frac{e_{b}}{\pi}+\frac{\sigma_{s}}{4 \pi} \int_{0}^{4 \pi} i d \omega$

It should be noted that the symbol $i$ denotes radiant intensity in this section (but electrical current density in the other parts), $a$ and $\sigma_{s}$ are absorption and scattering coefficients, $s$ is displacement, and $\omega$ solid angle, $e_{b}=\sigma T^{4}$ black-body emissive power. The RTE balances the changes in intensity $i$ due to absorption and out-scattering, emission, and in-scattering (Beale (2005)). This equation can be solved using a discrete ordinate method (DOM) or a Monte Carlo (MC) method. Then the radiative heat flux can be calculated based on the calclated radiation intensity from the RTE. It should be noted that both DOM and MC methods are very expensive in terms of computational resources, and additional engineering assumptions are required to invoke simpler radiation models (Beale (2005), and Damm and Fedorov (2005)).

The radiation heat transfer in the SOFC electrodes is usually coupled to the overall energy conservation, Eq. (27), by an effective thermal conductivity (Damm and Fedorov (2005)),

$k_{e f f}=k+k_{r}=k+\frac{16 n^{2} \sigma T^{3}}{3 \beta_{r}}$

where $k$ is thermal conductivity, $\sigma$ the Stefan-Boltzmann constant $\left(5.67 \times 10^{-8} \quad \mathrm{Wm}^{-2} \mathrm{~K}^{4}\right), \quad \beta$ the spectrally averaged Rosseland-mean extinction coefficient to the medium (the gray and non-scattering medium), $n$ the refractive index of the medium. This approximation is considered appropriate for optically thick regions, i.e., for porous anode and cathode where the optical thickness $\tau \gg>1$ (Murthy and Fedorov (2003)). It should be mentioned that the above approximation is not valid near the boundary, and this limitation can be overcome by coupling the diffusion model with the Schuster-Schwartzchild two-flux approximation for boundaries of the optically thick medium. The twoflux approximation also provides a simple solution method for onedimensional radiation in an optically thin domain, e.g., in the electrolyte. If it is assumed that the intensity is composed of two homogeneous components such as $q^{+}$and $q^{-}$in the $+x$ and $-x$ directions, then the RTE can be reduced as (Beale (2005))

$\frac{d}{d x}\left(\frac{1}{a+\sigma_{s}} \frac{d \bar{q}}{d x}\right)=4 a\left(\bar{q}-e_{b}\right)$

where $\bar{q}=\left(q^{+}+q^{-}\right) / 2$, and for which the radiant heat flux, $q_{r}=q^{+}-q^{-}$, may be computed as

$$
q_{r}=-\frac{1}{a+\sigma_{s}} \frac{d \bar{q}}{d x}
$$

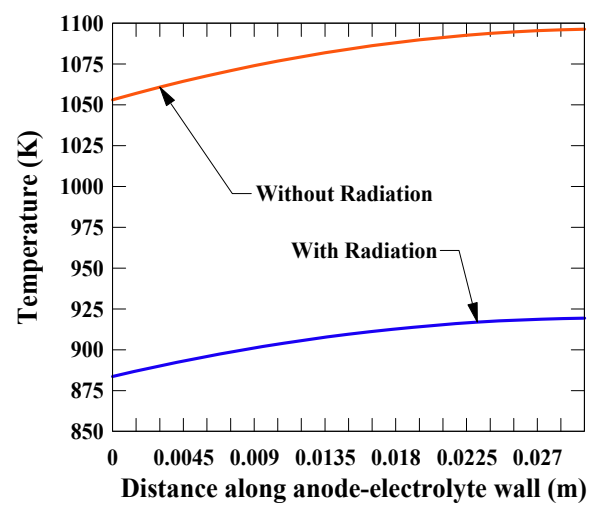

Fig. 10 Temperature distribution on the electrode-electrolyte walls with and without accounting for thermal radiation heat transfer (Murthy and Fedorov (2003)).

As revealed in Murthy and Fedorov (2003), the exclusion of thermal radiation effects in the electrolyte could result in overprediction of temperatures by as much as $100-200 \mathrm{~K}$ for the case of an electrolyte-supported SOFC, as shown in Fig. 10.

For the air and fuel ducts, one needs to consider emission and reflection of radiation by the surfaces as well as its extinction (absorption and scattering) and emission by the flowing gases. It should be noted that the air and fuel gases for SOFCs have been usually treated as non-interacting (transparent) with thermal radiation at the moderate pressures and temperatures (Damm and Fedorov (2005)), and surfaceto-surface radiation is thus the only thermal radiative transfer mode that must be considered in the flow duct of SOFCs. Certain assumptions are usually involved in the analysis, for example, the surfaces are opaque, gray, diffuse emitters, and reflectors of thermal radiation. However, one of the surfaces is a porous wall of the electrode, as shown in Fig. $1 b$, and this assumption may be questionable and the analysis becomes more complex. It is particularly true when the tubular cell design is concerned, because the thermal radiation is between the surfaces of two concentric tubes, the air supply tube and the porous support tube. In this case, the black surface approximation would not generally be appropriate. One way to release this assumption is to assign an apparent emissivity to the porous electrode interface, which can be calculated or measured by considering the entire porous layer (Damm and Fedorov (2005)). When the radiative heat flux at the surface is calculated, it can be incorporated into the overall energy conservation by the source terms or through the boundary conditions at the surfaces (Damm and Fedorov (2005)). 


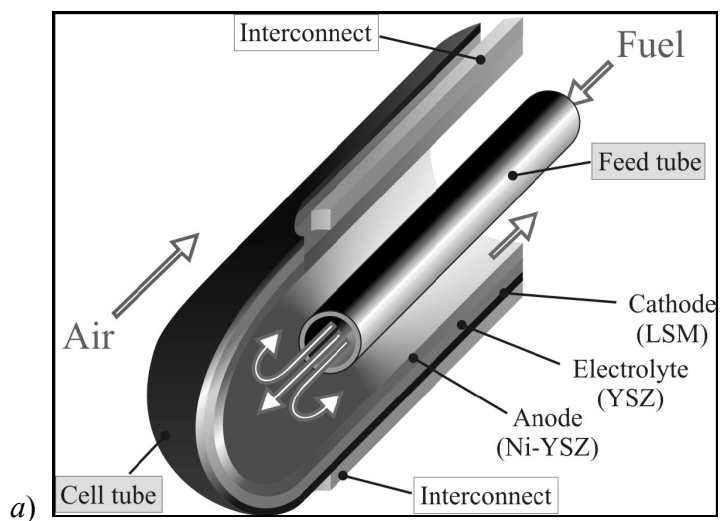

a)

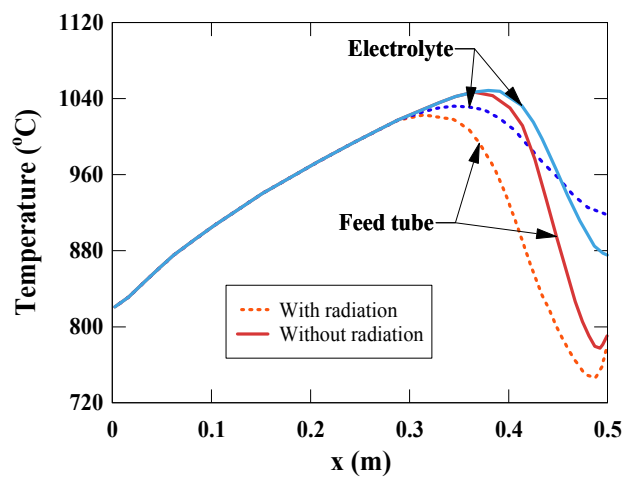

b)

Fig. $11 a$ ) Schematic view, and $b$ ) local temperature of a tubular SOFC with internal reforming (Suzuki et al. (2005)).

By taking the absorption coefficient of the solid materials for the porous electrodes and neglecting the effects of participating media (such as electrodes, electrolyte and participating gases), the surface-tosurface radiation heat transfer is studied for a tubular SOFC, as shown in Fig. 11a. The thermal radiation between the inner surface of the cell tube and the outer surface of the feed tube is included to evaluate its role in transferring the heat generated by the electrochemical reactions at the tubular cell to the feed tube, i.e., to the reaction site of the endothermic fuel reforming. The effects of the thermal radiation on the local temperature distribution are shown in Fig. $11 b$. It is clear that there is a conspicuous non-uniformity of temperature inside the electrolyte and the feed tube. The predicted maximum (or hot spot) temperatures of the electrolyte and the feed tube reach about $1050^{\circ} \mathrm{C}$ for the case without the thermal radiation. When the thermal radiation is included in the analysis, there is no clear effect on the temperature distribution in the entry region along the cell length. However pronounced effects can be found in the remaining areas, for example, the hot spot temperatures decrease (about 20 to $30{ }^{\circ} \mathrm{C}$ ) for both electrolyte and feed tube, and temperature distributions are smooth, to indicate the noticeable contribution to the heat transfer between the cell surfaces (Suzuki et al. (2005)).

\subsubsection{PEMFC water management and two-phase flow modeling}

Water management in PEMFC is one of the major issues in PEMFCs. This is because during PEMFC operation anode gases can be dried out if the electro-osmosis transport rate is higher than that of back diffusion. Consequently the electrolyte membrane may become dehydrated and too resistive to conduct current. On the other hand, water is generated at the cathode active surface and transported to the cathode duct. Cathode flooding may occur when the water removal rate fails to reach its threshold transport/generation rate. Both dry-out and water flooding should be avoided, and various water management schemes have been proposed. It should also be noted that condensation can occur in the cathode duct when local vapor saturation condition occurs in the duct. During last few years, extensive effort has been expended upon the development of numerical models with less restrictive assumptions and more physical complexities, particularly in the direction of applying CFD to solve the complete set of conservation equations for the composite cathode ducts or unit-cells. The development and new advances were reported in the most recent reviews (Wang (2004), Cheddie and Munroe (2005), Yan et al. (2004), Faghri and Guo (2005), and Biyıkoğlu (2005)).

When condensation occurs the transport process becomes twophase, which besides flooding the cathode porous layer can considerably complicate the modeling procedure as no experimental results are available for two-phase flow in PEMFCs. Instead, much attention has been paid on numerical investigations to reveal the relationships between the water saturation, proton conductivity (ohmic loss), the level of catalyst flooding (activation loss), and the effective diffusivity of the porous layer (concentration loss), see Lister and Djilali (2005), You and Liu (2001), He et al. (2000), Nguyen (2000), Wang et al. (2001), and Djilali and Lu (2002).

Based on the methodologies to account for the liquid water motion and surface tension (capillary diffusion) effects, there are several types of models to treat liquid water formation/transport phenomena in PEMFCs, particularly in the porous electrodes. The porosity correction model simplifies the two-phase problem by neglecting the transport of liquid water. In this case, the local saturation level and temperature are calculated iteratively with the internal energy and density of the water. The volume fraction open to the gas phase is written as (Yuan and Sundén (2005)):

$\varepsilon_{g}=\varepsilon(1-s)$

where $\varepsilon$ is the porosity, $s$ the saturation level. This approach is particularly efficient when saturation levels are low (such as in the case with low relative humidities, very small pores and low current densities), and no additional transport equations are solved in this model. However, this model does not account for liquid water motion at all.

The second approach, namely the moisture diffusion model, treats the liquid water motion by the surface tension, and the liquid water phase is considered as a scalar species with no convection terms when it is incorporated into a CFD code (Lister and Djilali (2005)). This approach is rather simple since only one additional equation is required compared to the one-phase model. It should be mentioned that this approach cannot model inter-phase transfer of heat and species, and its application is limited to surface tension (the dominant force on the liquid), and/or the case of low capillary numbers (small pores and low permeability).

The mixture model has been extensively developed to include the effects of liquid water convection during last few years. In the mixture approach, the gas and liquid water transport is considered to share the same velocity field, and the interfacial tension effect is completely ignored. In this case, the total amount of water can be obtained by solving a single species equation, rather than specific ones for water vapour and liquid water. The water concentration is allowed for going beyond the saturation level by assuming supersaturation in the gas phase, or alternatively the extra water is in the form of liquid water. The vapour and liquid water fields can be calculated after a solution has obtained. It should be pointed out that relative mobility and other correction factors are often employed in the approach. This approach is best used when the gas pressure is the dominant force on the liquid water, or the capillary number is high (i.e., large pores and high permeability). Because liquid water and water vapour have different velocities in reality, there might be trouble to get converging solutions at high saturation condition. 
The true two-phase (or multi-fluid) model is a more rigorous one in which the two phases have different velocities, and the interfacial tension effect is accounted for. This model is developed for the conditions of high saturation due to large liquid resolution, and when the influence of the gas is equivalent to that of the surface tension. In this approach, each phase is modelled with its own set of field equations coupled by the relative permeability, which is sensitive to saturation and phase change. Depending on the local properties, the phase change between the water vapour and liquid water can be either evaporation or condensation. Generally, this approach solves the highest number of variables, but it also needs most computational resources.

It should be noted that, to complete the two-phase model, two methods are available to deal with the phase change rate between the water vapour and liquid water. The first one, the kinetic theory, is based on maximum amount of water vapour that can be accommodated at the vapour/liquid interface. The maximum rate of evaporation for liquid water can then be determined based on the approximation of the evaporation/condensation coefficient. While for the second method, the liquid water is assumed to exist in the form of a spherical droplet, and the mass transfer is determined from the diffusion rate between the bulk water vapour and the surface of the droplet by employing a mass transfer Nusselt number as a measure of the droplet's ability to exchange mass (Lister and Djilali (2005)).

To properly model liquid water generation/transport/removal and analyse effects on PEMFC performance, several issues should be considered and implemented into the future modelling. One of these is the catalytic surface coverage by the liquid water; while another one is liquid water transport through hydrophobic porous layer, because teflonation of the carbon fiber paper is essential for water removal in PEMFC cathode, and it significantly complicates the prediction of capillary pressure, as revealed in Wang (2004) and Khan (2009).

\subsubsection{SOFC internal reforming reactions and modeling}

During recent years, one of the new trends is to reduce the SOFC operating temperature to a moderate range (from $1000{ }^{\circ} \mathrm{C}$ to $800{ }^{\circ} \mathrm{C}$ ) by employing a thick porous layer $(1.5-2 \mathrm{~mm})$ as the supporting structure. The size of the porous anode for this new design is bigger than that of the flow duct in terms of thickness and cross-sectional area. If hydrocarbon fuels are used, it is a fact that the heat required to maintain internal steam reforming can be provided by the electrochemical reactions. There are several advantages to have internal steam reforming of employed hydrocarbon fuels, for instance, the energy conversion efficiency will be much higher, and this benefit does not appear if the pure hydrogen is considered as the fuel. Moreover, close coupling of the internal reforming and the electrochemical reactions at the anode gives good heat transfer. Furthermore, hydrogen and $\mathrm{CO}$ are utilized by the cell as soon as they are produced by the reforming reaction, and the steam produced by the electrochemical reaction can be used in the reforming reaction as well. However, most of the internal reforming reaction takes place in the porous anode next to the fuel gas flow duct due to the high methane conversion rate, and very little methane reaches the active surface between the electrolyte and the porous anode. The endothermic internal reforming reaction and the exothermic electrochemical reactions are separated, and consequently may lead to large temperature gradients in the porous layer (Yuan and Sundén (2005), and Yuan and Sundén (2006)).

The source term $S_{m}$ in Eq. (14) accounts for the mass balance due to the electrochemical reactions at the active surface (bottom surface in Fig. 8):

$$
\begin{aligned}
& S_{m}=\left(J_{\mathrm{H}_{2}}+J_{\mathrm{CO}}+J_{\mathrm{H}_{2} \mathrm{O}}\right) \frac{A_{\text {active }}}{V} \\
& =\left(-\frac{I_{\mathrm{H}_{2}}}{2 F} M_{\mathrm{H}_{2}}-\frac{I_{\mathrm{CO}}}{2 F} M_{\mathrm{CO}}+\frac{I_{\mathrm{H}_{2}}+I_{\mathrm{CO}}}{2 F} M_{\mathrm{H}_{2} \mathrm{O}}\right) \frac{A_{\text {active }}}{V}
\end{aligned}
$$

where, $V$ refers to control volume, $\left(i_{H 2}+i_{C O}\right)$ is the total current density $I$ passing through the cell, $J$ the electrochemical reaction related mass flux. Commonly, the anode is based on nickel/zirconia cermet which can provide sufficient activity for the steam reforming and water-gas shift reactions without the need for any additional catalyst (Haberman and Young (2004)). There exist various reaction kinetics and rate/equilibrium constants reported in the literature for both the steam reforming and water-gas shift reactions. However, based on extensive reviews in (Haberman and Young (2004), and Aguiar et al. (2004)), it is found that the reforming reaction rate data presented in the literature varies greatly due to the use of different material structures and different amount of catalyst. In this work, the following reaction rates are employed to express the kinetic rates of absorption or production of the fuel gas species, based on partial pressure, temperature and species compositions:

$$
\begin{aligned}
& R_{r}=k_{r}^{+} P_{\mathrm{CH}_{4}} P_{\mathrm{H}_{2} \mathrm{O}}-k_{r}^{-} P_{\mathrm{CO}}\left(P_{\mathrm{H}_{2}}\right)^{3} \\
& R_{S}=k_{S}^{+} P_{\mathrm{CO}} P_{\mathrm{H}_{2} \mathrm{O}}-k_{S}^{-} P_{\mathrm{CO}_{2}} P_{\mathrm{H}_{2}}
\end{aligned}
$$

in which, $k^{+}$and $k^{-}$are velocity constants of the forward and backward reactions, $P$ partial pressure. Then, $S_{s, i}$ in Eq. (25) reads:

$$
\begin{aligned}
& S_{s, H_{2}}=\left(3 R_{r}+R_{S}\right) M_{H_{2}} ; S_{s, C H_{4}}=-R_{r} M_{C H_{4}} ; \\
& S_{s, H_{2} O}=\left(-R_{r}-R_{S}\right) M_{H_{2} O} ; S_{s, C O}=\left(R_{r}-R_{S}\right) M_{C O}
\end{aligned}
$$

As for the kinetics of the natural gas reforming reaction on nickel cermet SOFC anodes, extensive reviews can be found in (Haberman and Young (2004), and Aguiar et al. (2004)). It is common to employ the forward kinetic reforming reactions in the following form:

$$
k^{+}=k_{0} F\left(P_{i}\right) \exp \left(-\frac{E_{a}}{\Re T}\right)
$$

where $\mathfrak{R}$ is the universal gas constant with unit $J /($ mol $K), F$ the function of the species partial pressure, while $E_{a}$ stands for the activation energy, $k_{0}$ the pre-exponential constant. It is revealed that the first order kinetic expression is considered typical of direct internal reforming reaction in SOFC performance (Aguiar et al. (2004)). The following expressions employed in (Haberman and Young (2004)) are adopted in this work:

$$
k_{r}^{+}=2395 \exp (-231266 / \Re T)
$$

$$
k_{s}^{+}=0.0171 \exp (-103191 / \Re T)
$$

The backward kinetics $k_{r}^{-}$and $k_{s}^{-}$can be determined based on the following equilibrium constants $K_{e}$ for the two reactions,

$K_{e r}=\frac{k_{r}^{+}}{k_{r}^{-}} ; K_{e s}=\frac{k_{s}^{+}}{k_{s}^{-}}$

which are functions of temperature given by the following empirical equations (Haberman and Young (2004)):

$$
\begin{aligned}
& K_{e r}=1.0267 \times 10^{10} \times \exp \left(-0.2513 Z^{4}\right. \\
& \left.+0.3665 Z^{3}+0.5810 Z^{2}-27.134 Z+3.27770\right)
\end{aligned}
$$




$$
\begin{aligned}
& K_{e s}=\exp \left(-0.2935 Z^{3}+0.6351 Z^{2}+4.1788 Z+0.3169\right) \\
& Z=\frac{1000}{T}-1
\end{aligned}
$$
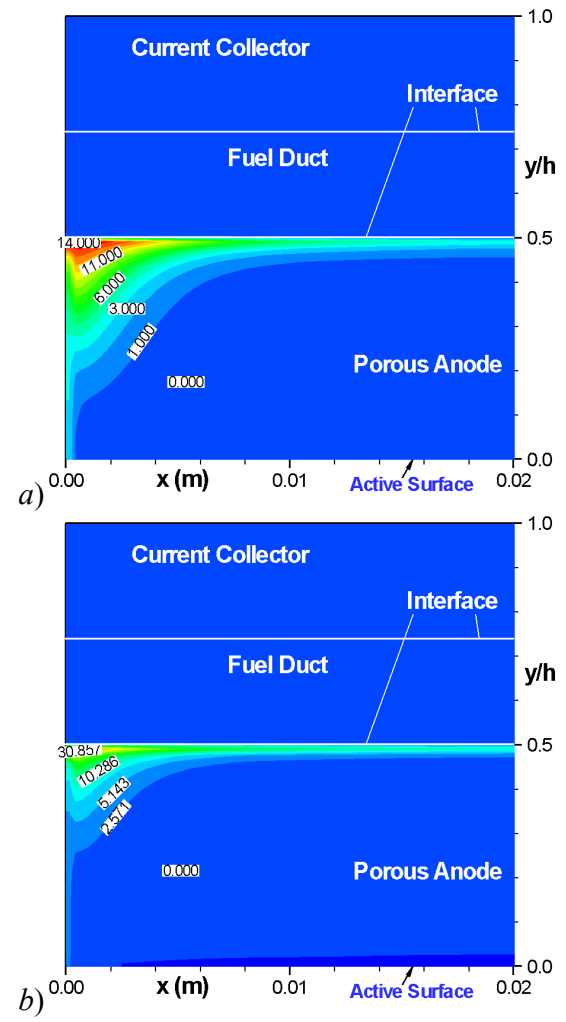

Fig. 12 Distribution of: $a$ ) steam reforming reaction rate $R_{r}$; and $b$ ) shift reaction rate $R_{s}$ along main flow direction in ITSOFC.

Both the predicted steam reforming and the water-gas shift reaction rates are shown in Figs. $12 a$ and $b$, respectively. It is found that both reactions are strong at the interface and the entrance regions within the porous layer close to the fuel flow duct (with a large reaction rate value). No reactions can be observed in the rest of the porous anode, particularly after a certain distance downstream the inlet. The distance for this specific case is about half the duct length.

The steam reforming reaction rates are plotted in Fig. 13 for cross sections at the inlet, the one-fourth and the half length from the inlet, respectively. It is found that, in a cross section, $R_{r}$ has maximum values in the regions close to the fuel flow duct, and small values or even noreaction appear in the rest of the porous anode. This is so because there is strong fuel gas permeation to the porous anode due to large pressure gradients (Yuan et al. (2003)). It is also observed that these maximum values decrease along the main flow direction, i.e., the maximum reaction rates are about 15,10 and $5.4 \mathrm{~mol} /\left(\mathrm{m}^{3} \mathrm{~s}\right)$ for Figs. $13 a, b$ and $c$, respectively. There is no steam reaction for most of the porous anode at the station of the half length from the inlet, as shown in Fig. $13 c$, because the methane is completely reformed. It should be mentioned that a similar trend is found for the water-gas shift reaction rate distribution (not shown here).

\subsection{Other Critical Issues Relating to CFD Approach}

Firstly, a CFD approach involves various material and transport properties in the governing equations, and the property characterization is extremely important for accurate prediction of the fuel cell performance. There are several groups of properties, such as transport properties of electrolyte/electrodes, electrokinetic ones for catalyst materials, thermodynamic and transport properties of reactants and products.

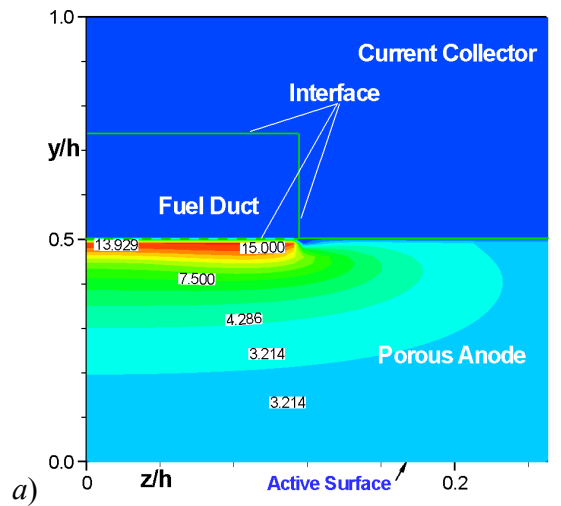

a)

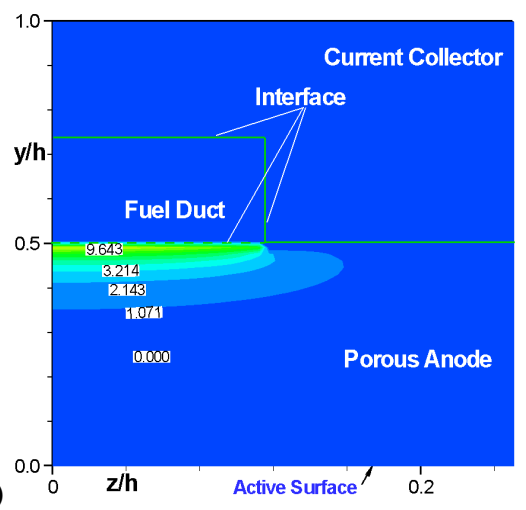

b)

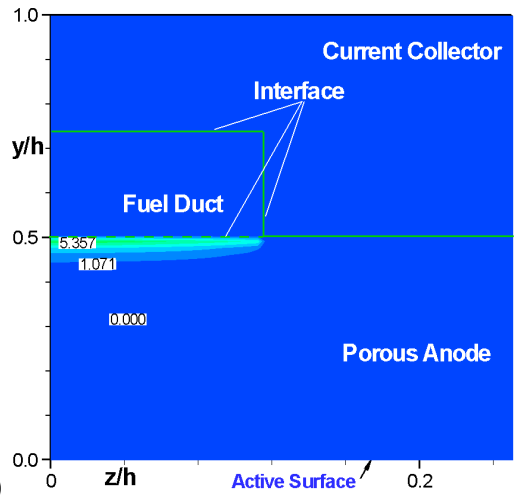

Fig. 13 Cross-sectional steam reforming reaction rate $R_{r}$ distribution at: $a$ ) the inlet; $b$ ) the one-fourth; and $c$ ) the half length from the inlet of an ITSOFC duct.

For PEMFCs, the ionic conductivity is one of the most important properties, because water and proton transport in membrane occurs concurrently. The strong dependence of electrolyte conductivity on water content has been studied, and various relations are available to take this effect into account (Wang (2004)). The water diffusion coefficient and electro-osmotic coefficient are the important properties as well, because these two parameters significantly affect the water content profile within the membrane and thus design of a proper water management scheme for PEMFCs.

For the catalyst layer, the important properties are the specific interfacial area, the exchange current density of the oxygen reduction reaction and the Tafel slop of this reaction. While for current collector plate, the important ones are electric conductivity, thermal conductivity and its surface wettability. These properties can be found in literature or in well documented text books. 
Another critical issue significant to fuel cell modelling is the catalytic reactions appeared in functional materials, particularly when the hydrocarbon fuels are used in SOFCs. In order to simplify the calculations, the available models conventionally treated the catalytic reforming and the water-gas shift reactions of the hydrocarbon fuels within the SOFC anodes as global kinetics reactions, or even assumed to be locally equilibrated. However the adsorption-desorption processes involve many surface reactions and surface (or intermediate) species transport phenomena at micro- or even nano-scale, as reviewed by Andersson et al. (2010).

Mass diffusion is a process leading to a uniform substance concentration or establishing an equilibrium gas distribution that results from random migration of the species. Molecular diffusion occurs as a result of thermal motion of the molecules, and proceeds at a maximum rate in gases, at a lower rate in liquids, and at a still lower rate in solid (Mostinsky (1996)). In the general case, the molecular diffusion flux of the species $i$ in the species conservation equation is proportional to the concentration gradient and diffusion coefficient. One of the significant challenges in fuel cell modelling is to determine the rate at which the species diffuse and gases convect in the gas flow ducts and porous electrodes. This requires knowledge of multi-component diffusion in the fuel gas flow ducts, particularly in the porous layers. In the literature, there are several basic approaches for determining the molar diffusion flux $\dot{\mathbf{n}}_{i}$ and converting to mass diffusion flux $\dot{\mathbf{m}}_{i}$ via the species molar mass, i.e., $\dot{\mathbf{n}}_{i}=\dot{\mathbf{m}}_{i} / M_{i}$. Fick's law, represented by $\dot{\mathbf{n}}_{i}=-\rho D_{i, j} \nabla X_{i}$ based on binary diffusion coefficient $D_{i, j}$ and molar fraction $X_{i}$, is the simplest diffusion model and is typically used in binary or dilute system (Mostinsky (1996)). A multi-component extension of Fick's law is sometimes used in the literature as well, e.g., in Ferguson et al. (1996),

$\dot{\mathbf{n}}_{i}=-\rho D_{i, j} \nabla X_{i}+X_{i} \sum_{i=1}^{n} \dot{\mathbf{n}}_{j}$

while the Stefan-Maxwell model is more commonly used in multicomponent system. The diffusion coefficients of species $i$ in the fuel gas flow duct is calculated by the expression based on the binary coefficients (Mostinsky (1996))

$D_{A, g m}=\frac{1-X_{A}}{X_{B} / D_{A B}+X_{C} / D_{A C}+\ldots}$

where $D_{A}$ is the diffusion coefficient of the component $A$ in the mixture with $B, C, \ldots, X_{A}, X_{B}, X_{C}$ are the molar fraction of the appropriate species, and $D_{A B}$ and $D_{A C}$ are the diffusion coefficients in the $A B$ and $A C$ binary system, respectively. It is clear that for an $n$ component system, $n(n-1) / 2$ binary diffusivities are required.

For the porous layer, molecular diffusion is predominant in the case with large pores, whose size is much bigger than the mean freepath of molecules. In this case, the diffusion can be described as presented above for the fuel gas flow duct. Knudsen diffusion occurs in the porous layer with small pores or under low pressure when the mean free-path of molecules is larger than the pore size, and the molecules collide with the walls more often than between themselves. In order to calculate the Knudsen diffusion flux, the coefficient $D_{i, k}$ is calculated based on the free molecule flow theory (Mostinsky (1996)):

$D_{i, k}=\frac{2}{3} r_{e} v_{i}=\frac{2}{3} r_{e}\left(\frac{8 \Re T}{\pi M_{i}}\right)$

in which $r_{e}$ is the effective radius and $v_{i}$ the average molecular speed of the $i$ th fuel species. To account for the reduction in the cross-sectional area and the increased diffusion length due to the tortuous paths of real pores in the porous electrodes, the effective diffusion coefficient can be evaluated (Haberman and Young (2004), and Mostinsky (1996)):

$D_{i, e f f}=\frac{\varepsilon}{\tau}\left(\frac{D_{i, g m} \times D_{i, k}}{D_{i, g m}+D_{i, k}}\right)$

where $\varepsilon$ is the porous porosity, $\tau$ tortuosity.

Another challenge related to CFD modelling is the requirement for a large number of computational elements, and parallel computing technique is required, particularly for industrial-scale cells. For instance, a cell involving 20-60 ducts needs 2-6 million grid points to sufficiently resolve each of the concerned regions, while the majority of the CFD work published to date has used no more than a few hundred thousand grid points (Wang (2004)). A parallel computational technique is therefore essential for this case.

During recent years, reliable commercial fuel cell codes (or in some cases, a fuel cell module added to an already existing software) have been developed. For instance, detailed SOFC and PEMFC models have been included in the Chemical Engineering Module of Comsol (Comsol (2009)), based on the platform of the MathWorks simulation code MATLAB. More detailed modules associated with other commercial codes are being further developed and incorporated into standard cell and stack modelling (Faghri and Guo (2005)). Fluent released a 3-D hydrogen PEMFC module to solve transport equations of flow, energy, species and electro-potential in the composite domain, together with contact resistance, joule heating, and time varying operating conditions, etc. Recently, ANAYS/FLUENT fuel cell modules were released as well. Similar development happened for other commercial packages as well, e.g., CFD-ACE+ and STAR-CD.

\section{TRANSPORT PROCESSES IN FUEL CELL STACKS}

As mentioned above, most theoretical fuel cell models found in the literature predict the electrochemical and thermo-fluid-dynamic performance based on specific fuel cell local characteristics, such as gas concentration, temperature, pressure, etc. The equations representing these characteristics can be, for example, in the form a differential form, and are locally discretized and solved using a mesh as in CFD approaches. It is obvious that the obtainable results can be very useful for the purpose of guiding future fuel cell research, and particularly components improvement/optimization.

However, for the case of the fuel cell stack and system study, most of these local data are not so useful if the model has to compare different stack configurations (tubular, planar and monolithic) and system balance, because the CFD methods are often complex and time consuming. In fact, overall discharge characteristics, such as outlet gas composition and temperature, electric current and power generation, are required to assess the stack performance. This can be achieved by an easy and reliable model in applying the local equations as "global" (Bove et al. (2005)).

An SOFC electrochemical black-box model was developed in (Bove et al. (2005)), based on a straight-forward simulation, where the effect of different fuel utilizations were evaluated. If the current provided by the SOFC stack is set as an input variable, different fuel utilization means different fuel flow rate to the stack, which is quantified using the coefficient of fuel and oxygen utilization:

$u_{f}=\frac{I / 2 F}{m_{H_{2}}+m_{C O}} ; u_{o x}=\frac{I / 4 F}{m_{O_{2}}}$

Once the initial values for $u_{f}$ and $u_{o x}$ are set, the SOFC performances are calculated, in terms of voltage and electric power. The cathodic and anodic outlet compositions were calculated based on the electrochemical reaction (Eq. (3)), while the gas outlet temperature 
was obtained using an energy balance based on a macro-balance equation:

$$
\begin{aligned}
& \mathrm{m}_{\text {in,anode }} h_{\mathrm{in}, \text { anode }}+\mathrm{m}_{\mathrm{in}, \text { cathode }} h_{\mathrm{in}, \text { cathode }}= \\
& \mathrm{m}_{\text {out }, \text { anode }} h_{\text {out }, \text { anode }}+\mathrm{m}_{\text {out }, \text { cathode }} h_{\text {out }, \text { cathode }}-V I-Q_{\text {loss }}
\end{aligned}
$$

If the difference between the desired and the computed one is larger than a maximum allowable value, a different oxidant flow rate is employed. The SOFC stack performance, in terms of $V-I$ and $P-I$, are compared specifying inlet or outlet gas compositions and a mean value between the previous two. It should be mentioned that the open circuit voltage is expressed by the Nernst equation corrected by the electron conduction and the cross-over of the cathodic gas into the anode based on a semi-empirical method (Bove et al. (2005)).

Another lumped model is developed using semi-empirical equations for PEMFC stack to estimate overall performance in terms of operating conditions with reduced calculation requirement (AlBaghdadi (2005)). The Nernst equation is expressed as:

$$
\begin{aligned}
& E=1.229-0.85 \times 10^{-3}(T-298.15) \\
& +4.3085 \times 10^{-5} T\left[\ln \left(P_{H_{2}}\right)+\frac{1}{2} \ln \left(P_{O_{2}}\right)\right]
\end{aligned}
$$

where $P$ is the partial pressure terms related to the hydrogen and oxygen concentrations at the anode and cathode. The activation overpotential is expressed as:

$$
\begin{aligned}
& \eta_{a c t}=-0.9514+0.00312 T+7.4 \times 10^{-5} T\left[\ln \left(C_{O_{2}}\right)\right] \\
& -0.000187 T[\ln (i)]
\end{aligned}
$$

in which, the effective oxygen concentration at the cathode catalyst sites is approximated by

$$
C_{O_{2}}=\frac{P_{O_{2}}}{5.08 \times 10^{6} \exp \left(\frac{-498}{T}\right)}
$$

while the partial pressure of oxygen at the water-gas interface is related to the water concentration at the cathode duct:

$$
P_{\mathrm{O}_{2}}=\left(P_{\text {sat }}\right)\left[\frac{1}{\exp \left(\frac{4.192 \times i}{T^{1.334}}\right) x_{\mathrm{H}_{2} \mathrm{O}}}-1\right]
$$

A similar approach as employed in Al-Baghdadi (2005) was also applied to evaluate the ohmic and mass concentration overpotentials (Mohamed and Jenkins (2004)). The results of the model indicated that the operating temperature and pressure can be optimized, based on cell performance for a given design and other operating conditions. PEMFC stack does not have to be operated at its maximum power, where the efficiency is the lowest as shown in Mohamed and Jenkins (2004) (the operating pressure effect on the stack performance). It is revealed that the cathode pressure is more effective to the PEMFC performance than anode pressure.

For stand alone power supply systems, the PEMFC stack was configured so that it delivers the maximum power output at the load's operating voltage by applying the algorithms in (Baschuk and $\mathrm{Li}$ (2005)). The stack design was optimized by searching the best configuration in terms of number of cells and cell surface area, and the model parameters were obtained by fitting the mathematical model to experimental data. For example, the stack voltage reads:

$$
\begin{aligned}
& V_{s}=Z\left(V_{0}-\eta_{\text {act }}-\eta_{\text {ohm }}-\eta_{\text {con }}\right) \\
& =Z\left[V_{0}-A \ln \left(\frac{I+I_{n}}{i_{0}}\right)-r\left(I+I_{n}\right)+B \ln \left(1-\frac{I+I_{n}}{I_{L}}\right)\right]
\end{aligned}
$$

$Z$ is the number of series connected cells in the stack, $\eta$ is the voltage drop, $I$ the current density, $r$ the area specific resistance in $\mathrm{k} \Omega \mathrm{cm}^{2}$. It should be noted that the limiting current density $I_{L}$ is at which the cell voltage falls rapidly due to the concentration effect, while $I_{n}$ represents the voltage drop due to fuel crossover and internal currents. The stack model was first fitted by an experiment based on an education solar hydrogen test rig for the parameters as follows:

Table 2: The Fitted Parameters Employed in PEMFC Stack Model (Mohamed and Jenkins (2004)).

\begin{tabular}{|l|l|l|l|l|l|l|l|}
\hline Parameter & $E_{O}$ & $A$ & $I_{n}$ & $I_{0}$ & $r$ & $B$ & $I_{L}$ \\
\hline Value & 1.04 & 0.05 & 1.26 & 0.2 & $9.8 \times 10^{-5}$ & 0.08 & 129 \\
\hline
\end{tabular}

The model was further employed to configure the stack to supply the right amount of power of $730 \mathrm{kWh}$ per year operating on $12 \mathrm{~V} \mathrm{dc}$ in a family house, in terms of number of cells in series and in parallel, and the cell surface area. The algorithm code was developed using MATLAB, and took only 2 minutes to arrive at an optimal solution.

Based on a hydraulic network analysis, the distribution of the pressure and mass flow rate for the fuel and oxidant streams in PEMFC stacks is modelled in Baschuk and Li (2005), with two common stack configurations. A $U$ stack is designed such that the reactant streams enter and exit the stack at the same end, while a $\mathrm{Z}$ stack has reactant streams entering and exiting on opposite ends. Both designs consist of 50 individual active cells.

The reactant distribution within the stack is modelled by treating the stack manifold and gas flow ducts as a pipe network. The stack voltage $V_{\text {stack }}$ was obtained by

$V_{\text {stack }}=\sum_{1}^{N_{\text {cell }}} V_{\text {cell }}-\sum_{1}^{N_{\text {cell }}} \eta_{c p}$

where $N_{\text {cell }}$ is the total number of the fuel cells in the stack, $\eta_{c p}$ the ohmic loss due to the cooling plate. Based on the simulated reactant flow rate and pressure distribution, the cell-to-cell voltage variation is predicted for both $\mathrm{U}$ and $\mathrm{Z}$ configuration stacks. It should be noted that the single cell voltage operating independently is about $0.6 \mathrm{~V}$. Near the stack inlet and outlet, the cells of the $\mathrm{Z}$ configuration stack have a higher voltage than the single cell, while only the cells near the stack inlet have a higher performance for the $U$ configuration design. It is interesting to note that the majority of the cells in the stacks have voltages less than the single cell, which results in the average cell voltage of the stack being less than the single cell voltage. As revealed in Baschuk and Li (2005), the performance differential could be eliminated by ensuring that each cell in the stacks has the same mass flow rate, and relevant approaches to achieve it are concluded.

\section{APPROACHES FOR ANALYSING FUEL CELL SYSTEMS}

Several types of fuel cell system configurations have been hypothesized and tested at the conceptual level but hybrid power plants are the most efficient ones. These are designs that combine a fuel cell cycle with other thermodynamic ones to provide higher efficiency. The heat rejected by the fuel cell at a high temperature is used in a bottoming cycle to generate steam or drive a gas turbine (in SOFCs).

By emergence of new technology (fuel cells), new concepts (coor tri-generation, hydrogen economy) and new fuels (biomass), the integrated energy system design/optimization becomes a critical issue, because the system configurations are unknown a priori. Generally, 
there are several objectives to formulate and define the optimal designs based on, e.g., thermodynamic, economic and environmental concerns. The thermodynamic concern is to realize the maximum energy efficiency, exergy efficiency, while the economic one is to minimize the investment cost, maximize profits, etc. The environmental consideration regards minimization of $\mathrm{CO}_{2}$ and $\mathrm{NO}_{\mathrm{x}}$ emissions, noise, life cycle analysis, and so on. The fuel cell system level modelling can be for the above mentioned single one, or for combined ones (e.g., thermo-economic optimization to constitute competing objectives).

Comprehensive thermodynamic models were developed for SOFC power systems fed by methane in Chan and Ding (2005), and PEMFC system Hussain et al. (2005), respectively, employing the lumped stack approach. The SOFC system studied consists of fuel cell stack, heat exchangers for preheating fuel and air streams, an afterburner to burn off the residual fuel, a vaporiser for vaporising water, a mixer for mixing fuel and steam, a reformer to produce hydrogen-rich reformate and a steam boiler serves to balance the heat of the power system, while the PEMFC system includes the air compressor, heat exchanger, humidifier and a cooling loop. A similar approach was presented in Omosun et al. (2005) for prediction of SOFC system efficiencies and costs. This system integrates an SOFC stack with biomass gasification for production of power and heat. The steady-state approach was developed in the gPROMS modelling tool, in which simple mass and energy balances for planar internal reforming SOFC are modelled based on the simplifications for major physical phenomena (Omosun et al. (2005)).

The fuel cell system integration is not only expressed in terms of material flows but also in terms of energy balance. There are several models employing process integration techniques combined with commercial process simulation packages, e.g., Belsim-VALI III in Godat and Marechal (2003), to analyze and improve the performance of an integrated PEMFC system including stack, fuel processing and postcombustion units. The fuel processing unit consists of a steam methane reformer (SMR), water gas shift (WGS) reactor (to transform the remaining $\mathrm{CO}$ into additional hydrogen at a lower operating temperature) and preferential oxidation reactor (PROX) (to convert the remaining $\mathrm{CO}$ into $\mathrm{CO}_{2}$ to avoid catalyst poisoning). This unit was modelled based on the assumptions that the reactions are near equilibrium and isothermal, and pressure drops neglected.

The PEMFC stack power is simply based on Nernst potential and ohmic overpotential, while the energy balance reads:

$\sum_{i=1}^{\text {inlets }} m_{i} h_{i}\left(T_{\text {cell }}, P_{\text {cell }}\right)-\sum_{o=1}^{\text {outlets }} m_{o} h_{o}\left(T_{\text {cell }}, P_{\text {cell }}\right)=P_{\text {el }}+Q_{F C}$

It should be mentioned that the PEMFC stack was also assumed to be isothermal and isobaric, and water migration through the membrane was neglected. The depleted hydrogen of the PEMFC stack is burned completely in the post combustion unit to supply heat for energy balance of the fuel processing unit.

By defining a list of hot and cold streams in the above mentioned units, the energy requirements were calculated based on the selected parameters, e.g., steam to carbon ratio, reforming temperature, operating temperature and pressure of PEMFC stack, fuel utilization and air excess. Afterwards, the system integration performances were simulated based on well developed process integration techniques without having to impose the heat exchange system design. The process integration technique (or the pinch technology) has been developed for analyzing the energy integration in industrial processes to help identify energy savings opportunities. This approach is typically applied in two steps, the first is a targeting phase that aims at identifying the minimum energy requirement of the system by computing the possible energy recovery from the hot streams to heat up the cold streams of the system, while the second step is the synthesis of the heat exchanger network that will implement the targeted energy recovery. The hot and cold streams define the system heat sources and requirements, respectively, that are characterized by a heat-temperature diagram, i.e., the heat sources and sinks are composed to compute the hot/cold composite curves that represent the heat availability/requirement in the system as a function of the temperatures. The composite curves can be considered as being one single hot/cold stream that will exchange heat in a virtual counter-current heat exchanger. The pinch point is that the maximum heat recovery by heat exchange can be realized when the hot and cold temperature difference maintains a minimum value $\Delta T_{m i n}$. Using the simplified PEMFC stack model together with the composite curve calculation, simulation of heat exchange network was performed to reveal the influence of the major decision variables and define the best system configuration (Godat and Marechal (2003)).
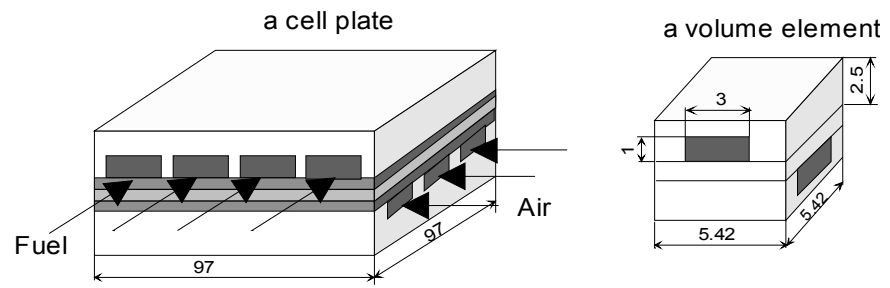

Fig. 14 Geometry characteristics of the planar SOFC (in mm).

The thermodynamic modelling of a combined SOFC and gas turbine $(\mathrm{SOFC} / \mathrm{GT})$ system was developed and implemented in the simulation software, Aspen Plus ${ }^{\circledR}$, for a reference design of around 500 kWe (Palsson et al. (2000)). For SOFC modelling, the finite volume method was used by discretizing the cell geometry into a number of repeating volume elements, as shown in Fig. 14. The dimensions of the volume element are chosen in such a way that the element contains part of the air channel, part of the fuel channel, and part of electrode /electrolyte structure. All the constitutive equations were formulated for the solid part and the gas phases of each element to balance the electrochemical and thermal performance. The algebraic equations were integrated through a relaxation method (SOR) to get SOFC performance parameters. The SOFC model was integrated into the system simulation tool as a user defined model, whereas other components constituting the system were modelled as standard unit operation models.

There are several studies on the dynamic modelling of fuel cell stacks, see Bhattacharyya and Rengaswamy (2009) and Andersson et al., (2010). One of the challengers in transient modelling is to capture the characteristic times ranging from the order of milliseconds (ions transport) to minutes or hours (energy transport in the stacks and the systems).

\section{CONCLUSIONS AND FINAL REMARKS}

Due to the complexity of fuel cells, fundamental understanding continues to be required for the coupled electrochemical and transport processes with two-phase flow/water management in PEMFCs and internal reforming reactions/thermal management in SOFCs, and this can be achieved by CFD based modeling approaches involving various interacting physicochemical submodels for the components and unitcells. When the primary purpose of the modeling is to provide fuel cell performance, and to analyze the whole integrated energy system, the physicochemical variations (such as gas concentration, temperature, pressure and current density) are less relevant compared to the performance parameters, in terms of power, heat and reactant requirements. In this case, the fuel cell stack is just a part of the whole system, with the purpose to generate certain outputs based on the supplied input, and the lumped parameter analysis approaches based on empirical or semi-empirical models are more suitable. In this paper, various kinds of methods for the modeling and analysis were discussed, together with their applicability and limitations. 


\section{ACKNOWLEDGEMENTS}

The European Research Council (ERC), the Swedish Energy Agency and the Swedish Research Council (VR) are acknowledged for financial support to projects related to this paper.

\section{NOMENCLATURE}

surface area of control volume at active site, $\mathrm{m}^{2}$

width of porous layer, $\mathrm{m}$

microscopic inertial coefficient, $1 / \mathrm{m}$

width of flow duct, $m$

pressure coefficient

specific heat capacity, $\mathrm{J} /(\mathrm{kg} \mathrm{K})$

molar diffusion coefficient of fuel gas species, $\mathrm{m}^{2} / \mathrm{s}$

hydraulic diameter, $\mathrm{m}$

black-body emissive power

overpotential, $\mathrm{V}$

activation energy, $\mathrm{kJ} / \mathrm{mol}$

Faraday constant $(96487 \mathrm{C} / \mathrm{mol})$ or the Forchheimer coefficient

$\Delta G \quad$ the Gibbs free energy change, $\mathrm{J} / \mathrm{kg}$

$f_{a p p} \quad$ apparent friction factor

$H \quad$ enthalpy, $\mathrm{J} / \mathrm{kg}$

$h$ heat transfer coefficient, $\mathrm{W} /\left(\mathrm{m}^{2} \mathrm{~K}\right)$; overall height of the duct, $\mathrm{m}$

$h_{w l} \quad$ water latent heat, $\mathrm{J} / \mathrm{kg}$

I current density, $\mathrm{A} / \mathrm{m}^{2}$

$J \quad$ electrochemical reaction related mass flux, $\mathrm{kg} /\left(\mathrm{m}^{2} \mathrm{~s}\right)$

$k \quad$ thermal conductivity, $\mathrm{W} /(\mathrm{m} \mathrm{K})$; reforming reaction velocity constants

$k_{0} \quad$ pre-exponential constant, -

$K_{e} \quad$ equilibrium constants, $\mathrm{Pa}^{2}$

$\dot{m} \quad$ mass diffusion flux, $\mathrm{kg} /\left(\mathrm{m}^{2} \mathrm{~s}\right)$

$M \quad$ molecular weight, $\mathrm{kg} / \mathrm{kmol}$

MEA membrane electrolyte assembly

$\mathrm{Nu} \quad$ Nusselt number

$\dot{n} \quad$ molar diffusion flux, $\mathrm{mol} /\left(\mathrm{m}^{2} \mathrm{~s}\right)$

$\alpha \quad$ net water transport coefficient

$\beta \quad$ spectrally averaged Rosseland-mean extinction coefficient $\beta_{i} \quad$ permeability of diffusion layer, $\mathrm{m}^{2}$

$\varepsilon \quad$ porosity

$\phi \quad$ arbitrary variable; electric potential, $\mathrm{V}$

$\eta \quad$ relative humidity, $\%$; overpotetial, $\mathrm{V}$

$\mu \quad$ dynamic viscosity, $\mathrm{kg} /(\mathrm{m} \mathrm{s})$

$v \quad$ kinematic viscosity, $\mathrm{m}^{2} / \mathrm{s}$

$\rho \quad$ density, $\mathrm{kg} / \mathrm{m}^{3}$

$\sigma \quad$ Stefan-Boltzmann constant $\left(5.67 \times 10^{-8} \mathrm{Wm}^{-2} \mathrm{~K}^{4}\right)$

$\sigma_{\text {eff }} \quad$ effective ionic/electric conductivity, $\mathrm{S} / \mathrm{cm}$

$\sigma \quad$ scattering coefficient

$\tau \quad$ tortuosity, -

Superscripts

$+\quad$ forward reaction

- $\quad$ reverse reaction

Subscripts

a anode or air

act activation

active at active site

av average

b bottom wall

bulk bulk fluid condition

$c \quad$ cathode

e electrolyte

eff effective parameter

$f \quad$ fluid or fuel

$\mathrm{CH}_{4}$ methane

$\mathrm{CO}$ hydrocarbon monoxide

$\mathrm{CO}_{2} \quad$ hydrocarbon dioxide

$e$ equilibrium

gm fuel gas mixture

$\mathrm{H}_{2} \quad$ hydrogen

$\mathrm{H}_{2} \mathrm{O}$ water vapor

in inlet

$k \quad$ Knudsen diffusion

$m$ mass transfer

ohm ohmic

$\mathrm{O}_{2} \quad$ oxygen

out outlet

$p \quad$ porous layer or permeation

$r \quad$ steam reforming reaction

$s \quad$ solid wall; shift reaction; species

trans mass transport

wall

sat saturation

\section{REFERENCES}

Aguiar, A., Adjiman, C.S. and Brandon, N.P., 2004, “Anode-supported Intermediate Temperature Direct Internal Reforming Solid Fuel Cell. I: Model-based Steady-state Performance", J. Power Sources, 138, 120136. doi:10.1016/j.jpowsour.2005.01.017

Al-Baghdadi, M.A.R.S, 2005, "Modeling of Proton Exchange Membrane Fuel Cell Performance Based on Semi-empirical Equations", Renewable Energy, 30, 1587-1599. doi:10.1016/j.renene. 2004.11.015

Andersson, D., Åberg, E., Yuan, J., Sundén, B. and Eborn, J., 2010, "Dynamic Modeling of a Solid Oxide Fuel Cell System in Modelica", FuelCell2010-33078, Proceedings of the ASME $20108^{\text {th }}$ Int. Fuel Cell Sci., Engn. Tech. Conference, New York, USA.

Andersson, M., Yuan, J. and Sundén, B., 2010, "Review on Modeling Development for Multi-scale Chemical-reactions-coupled transport phenomena in SOFCs", Applied Energy, 87, 1461-1476. doi:10.1016/ j.apenergy.2009.11.013 
Baschuk, J.J. and X. Li, 2000, "Modelling of Polymer Electrolyte Membrane Fuel Cells with Variable Degrees of Water Flooding", $J$. Power Sources, 86, 181-196. doi:10.1016/S0378-7753(99)00426-7

Baschuk, J.J. and Li, X., 2005, "Modeling of PEM Fuel Cell Stacks with Hydraulic Network Approach", Book chapter in Transport Phenomena in Fuel Cells, Sundén, B. \& Faghri, M. (eds), 283-315, WIT Press, UK.

Beale, S.B., 2005, "Numerical Model for Planar Solid Oxide Fuel Cells", Book Chapter in Transport Phenomena in Fuel Cells, Sundén, B. \& Faghri, M. (eds), 43-82, WIT Press, UK,.

Berning, T. and Djilali, N., 2003, "Three-dimensional Computational Analysis of Transport Phenomena in a PEM Fuel Cell- a Parametric Study", J. Power Sources, 124, 440-452. doi:10.1016/S0378-7753 (03)00816-4

Biyikoğlu, A., 2005, "Review of Proton Exchange Membrane Fuel Cell Models", Int. J. Hydrogen Energy, 30, 1181-1212. doi:10.1016/j.ijhydene.2005.05.010

Brouwer, J., Jabbari, F., Leal, E.M. and Orr, T., 2005, “Analysis of a Molten Carbonate Fuel Cell: Numerical Modeling and Experimental Validation", J. Power Sources, 158, 213-224. doi:10.1016/j.jpowsour. 2005.07.093

Bove, R., Lunghi, P. and Sammes, N.M., 2005, "SOFC Mathematic Model for Systems Simulations. Part One: from a Micro-detailed to Macro-black-box Model", Int. J. Hydrogen Energy, 30, 184-187. doi:10.1016/i.ijhydene.2004.04.008

Chan, S.H. and Ding, O.L., 2005, "Simulation of a Solid Oxide Fuel Cell Power System Fed by Methane", Int. J. Hydrogen Energy, 30, $167-$ 179, 2005. doi:10.1016/j.ijhydene.2004.04.001

Cheddie, D. and Munroe, N., 2005, "Review and Comparison of Approaches to Proton Exchange Membrane Fuel Cell Modeling", $J$. Power Sources, 147, 72-84. doi:10.1016/j.jpowsour.2005.01.003

Comsol Chemical Engineering, COMSOL documentation, 2009.

Damm, D.L., and Fedorov, A.G., 2005, "Radiation Heat Transfer in SOFC Materials and Components", J. Power Sources, 143, 158-165. doi:10.1016/j.jpowsour.2004.11.063

Debangsu B. and Raghunathan R. 2009, "A Review of Solid Oxide Fuel Cell (SOFC) Dynamic Models", Ind. Eng. Chem. Res., 48, 60686086. DOI: $10.1021 /$ ie $801664 j$

Djilali, N. and Lu, D., 2002, "Influence of Heat Transfer on Gas and Water Transport in Fuel Cells", Int. J. Therm. Sci., 41, 29-40. doi:10.1016/S1290-0729(01)01301-1

Dutta, S., Shimpalee, S. and Zee, J.W.V., 2000, "Three-Dimensional Numerical Simulation of Straight Channel PEM Fuel Cells", J. Appl. Electroche., 30, 135-146. doi: 10.1023/A:1003964201327

Faghri, A. and Guo Z., 2005, "Challenges and Opportunities of Thermal Management Issues Related to Fuel Cell Technology and Modeling", Int. J. Heat Mass Transfer, 48, 3891-3920. doi:10.1016/ j.ijheatmasstransfer.2005.04.014

Ferguson, J.R., Fiard, J.M. and Herbin, R., 1996, “Three-dimensional Numerical Simulation for Various Geometries of Solid Oxide Fuel Cells", J. Power Sources, 58, 109-122. doi:10.1016/03787753(95)02269-4

Godat, J. and Marechal, F., 2003, "Optimization of a Fuel Cell System Using Process Integration Techniques", J. Power Sources, 118, 411423. doi:10.1016/S0378-7753(03)00107-1

Haberman, B.A. and Young, J.B., 2004, “Three-dimensional Simulation of Chemically Reacting Gas Flows in the Porous Support Structure of an Integrated-planar Solid Oxide Fuel Cell", Int. J. Heat Mass Transfer, 47, 3617-3629. doi:10.1016/j.ijheatmasstransfer.2004.04.010

Haraldsson, K. and Vipke, K., 2004, "Evaluating PEM Fuel Cell System Models", J. Power Sources, 126, 88-97. doi:10.1016/ j.jpowsour.2003.08.044

Gundermann, M., Heidebrecht, P. and Sundmacherv, K., 2008, "Parameter Identification of a Dynamic MCFC Model Using a FullScale Fuel Cell Plant," Ind. Eng. Chem. Res., 47, 2728-2741. DOI: 10.1021/ie070951m.

He, W., Yi, J.S. and Nguyen, T.V., 2000, "Two-phase Flow Model of the Cathode of PEM Fuel Cells Using Interdigitated Flow Fields", AIChE Journal, 46, 2053-2064. doi: 10.1002/aic.690461016

Hussain, M.M., Baschuk, J.J., Li, X. and Dincer, I., 2005, "Thermodynamic Analysis of a PEM Fuel Cell Power System", Int. J. Thermal Sci., 44, 903-911. doi:10.1016/j.ijthermalsci.2005.02.009

Kakaç, S, Pramuanjaroenkij, A. and Zhou, X.Y., 2007, "A Review of Numerical Modeling of Solid Oxide Fuel Cells", Int. J. Hydrogen Energy, 32, 761-786. doi:10.1016/j.ijhydene.2006.11.028

Kazim, A., Liu, H.T. \& Forges, P., 1999, "Modelling of Performance of PEM Fuel Cells with Conventional and Interdigitated Flow Fields", $J$. Applied Electrochem., 29, 1409-1416. doi:10.1023/A:1003867012551

Kee, R.J., Korada, P., Walters, K. and Pavol, M., 2002, “A Generalized Model of the Flow Distribution in Channel Networks of Planar Fuel Cells", J. Power Sources, 109, 148-159. doi:10.1016/S03787753(02)00090-3

Khan, M.A., 2009, Numerical Simulation of Multi-scale Transport Processes and Reactions in PEM Fuel Cells Using Two-Phase Models, Thesis for the degree of Licentiate in Engn., Lund University, ISSN 0282-1990, Lund, Sweden.

Kreuer, K.D., 2003, "Proton-conducting Oxides", Annu. Rev. Mater. Res., 33, 333-359. doi:10.1146/annurev.matsci.33.022802.091825

Larminie, J. and Dicks, A., 2002, Fuel Cell Systems Expained, $2^{\text {nd }}$ Ed., John Will \& Sons Ltd., England.

Lehnert, W., Meusinger, J. and Thom, F., 2000, "Modelling of Gas Transport Phenomena in SOFC Anodes", J. Power Sources, 87, 57-63. doi:10.1016/S0378-7753(99)00356-0

Li, P.W., Schaefer, L. and Chyu, M.K., 2005, "Multiple Transport Processes in Solid Oxide Fuel Cells", Book Chapter in Transport Phenomena in Fuel Cells, Sundén, B. \& Faghri, M. (eds), 1-42, WIT Press, UK.

Lister, S. and Djilali, N., 2005, “Two-phase Transport in Porous Gas Diffusion Electrodes", Book Chapter in Transport Phenomena in Fuel Cells, Sundén, B. \& Faghri, M. (eds), WIT Press, 175-214.

Liu, H., Yuan, J. and Sundén, B., 2008, “Thermal Radiation and Effects on Transport Processes in Solid Oxide Fuel Cells", Heat Transfer Research, 39, 453-467. DOI: 10.1615/HeatTransRes.v39.i5.90

Meng, H. and Wang, C., 2004, "Electron Transport in PEFCs", J. Electrochem. Soc., 151, A358-367. doi: 10.1149/1.1641036

Mohamed, I. and Jenkins, N., 2004, "Proton Exchange Membrane (PEM) Fuel Cell Stack Configuration Using Genetic Algorithms", $J$. Power Sources, 131, 142-146. doi:10.1016/j.jpowsour.2004.01.012

Mostinsky, I.L., 1996, "Diffusion coefficient", in: International Encyclopedia of Heat \& Mass Transfer, Hewitt, G.F., Shires, G.L. and Polezhaev, Y.V. (eds.), CRC Press, Florida, USA. 
Murthy, S. and Fedorov, A., 2003, "Radiation Heat Transfer Analysis of the Monolith Type Solid Oxide Fuel Cell", in: Proceedings of IMECE03, 2003 ASME International Mechanical Engineering Congress, Washington, D.C.

Nguyen, T.V., 2000, "Modeling Two-Phase Flow in the Porous Electrodes of Proton Exchange Membrane Fuel Cells Using the Interdigitated Flow Fields", Proc. Electrochem. Soc., 99-14, 222-241.

Omosun, A.O., Bauen, A., Brandon, N.P., Adjiman, C.S. and Hart, D., 2004, "Modelling System Efficiencies and Costs of Two Biomassfueled SOFC System", J. Power Sources, 131, 96-106. doi:10.1016/j.jpowsour.2004.01.004

Okada, T., Xie, G. and Meeg, M., 1998, "Simulation for Water Management in Membranes for Polymer Electrolyte Fuel Cells", Electrochem. Acta, 43, 2141-2155. oi:10.1016/S0013-4686(97) $\underline{10099-8}$

Palsson, J., Selimovic, A., and Sjunnesson, L., 2000, “Combined Solid Oxide Fuel Cell and Gas Turbine Systems for Efficient Power and Heat Generation", J. Power Sources, 86, 442-448. doi:10.1016/S0378-7753 (99)00464-4

Shimpalee, S. and Dutta, S., 2000, "Numerical Prediction of Temperature Distribution in PEM Fuel Cells", Num. Heat Transfer (Part A), 38, 111-128. DOI: 10.1080/10407780050135360

Singh, D., Lu, D.M. and Djilali, N., 1999, "A Two-Dimensional Analysis of Mass Transport in Proton Exchange Membrane Fuel Cells", Int. J. Eng. Sci., 37, 431-42. doi:10.1016/S0020-7225(98)00079-2

Suzuki, K., Iwai, H. and Nishino, T., 2005, "Electrochemical and Thermo-Fluid Modeling of a Tubular Solid Oxide Fuel Cell with Accompanying Indirect Internal Fuel Reforming”, Book Chapter in Transport Phenomena in Fuel Cells, Sundén, B. \& Faghri, M. (eds), 83131, WIT Press, UK.

Um, S., Wang, C.Y. and Chen, K.S., 2000, "Computational Fluid Dynamics Modeling of Proton Exchange Membrane Fuel Cells", $J$. Electrochem. Soc., 147, 4485-4493. doi:10.1149/1.1394090

Versteeg, H.K. and Malalasekera, W., 2007, An Introduction to Computational Fluid Dynamics - the Finite Volume Method, $2^{\text {nd }}$ ed., Longman Group Ltd, England.

Vogler, M., Bieberle-Hütter, A., Gauckler, L, Warnatz, J. and Bessler, W.J., 2009, "Modelling Study of Surface Reactions, Diffusion, and Spillover at a Ni/YSZ Patterned Anode", J. Electrochem. Soc., 156, B663-B672. doi: 10.1149/1.3095477

Voss, H.H., Wilkinson, D.P., Pickup, P.G., Johnson, M.C. and Basura, V., 1995, "Anode Water Removal: a Water Management and Diagnostic Technique for Solid Polymer Fuel Cells", Electrochimica Acta, 40, 321-328. doi:10.1016/0013-4686(94)00266-4
Wang, C.Y., 2004, "Fundamental Models for Fuel Cell Engineering", Chem. Rev., 104, 4727-4766. DOI: 10.1021/cr020718s

Wang, Z.H., Wang, C.Y. and Chen, K.S., 2001, "Two-Phase Flow and Transport in the Air Cathode of Proton Exchange Membrane Fuel Cells", J. Power Sources, 94, 40-50. doi:10.1016/S0378-7753(00) $\underline{00662-5}$

Yan, V.M., Chen, F., Wu, H.Y., Soong, C.Y. and Chu, H.S., 2004, "Analysis of Thermal and Water Management with Temperaturedependent Diffusion Effects in Membrane of Proton Exchange Membrane Fuel Cells", J. Power Sources, 129, 127-137. doi:10.1016/i.jpowsour.2003.11.028

Yao, K.Z., Karan, K., McAuley, K.B., Oosthuizen, P., Peppley, B. and Xie, T., 2004, "a Review of Mathematical Models for Hydrogen and Direct Methanol Polymer Electrolyte Membrane" Fuel Cells, 4, 3-29. doi:10.1002/fuce.200300004

You, L. and Liu, H. 2001, "A Two-phase and Multi-Component Model for the Cathode of PEM Fuel Cells", Proceedings of ASME IMECE2001/HTD-24273, 1-10.

Yuan, J., Faghri, M. and Sundén, B., 2005, "On Heat and Mass Transfer Phenomena in PEMFC and SOFC and Modeling Approaches", Book Chapter in Transport Phenomena in Fuel Cells, Sundén, B. \& Faghri, M. (eds), 133-174, WIT Press, UK.

Yuan, J., Huang, Y., Sundén, B. and Wang, W.G., 2009, "CFD Approach to Analyze Parameter Effects on Chemical-Reacting Transport Phenomena in SOFC Anodes", Heat and Mass Transfer, 45, 471-484. doi: 10.1007/s00231-008-0449-6

Yuan, J., Rokni, M. and Sundén, B., 2001, "Simulation of Fully Developed Laminar Heat and Mass Transfer in Fuel Cell Ducts with Different Cross Sections", Int. J. Heat Mass Transfer, 44, 4047-4058. doi:10.1016/S0017-9310(01)00052-7

Yuan, J., Rokni, M. and Sundén, B., 2003, "Three-Dimensional Computational Analysis of Gas and Heat Transport Phenomena in Ducts Relevant for Anode-Supported Solid Oxide Fuel Cells", Int. J. Heat Mass Transfer,46,809-821.doi:10.1016/S0017-9310(02)00357-5

Yuan, J. and Sundén, B., 2005, "Analysis of Intermediate Temperature Solid Oxide Fuel Cell Transport Processes and Performance", ASME J. Heat Transfer, 27, 1380-1390. doi: 10.1115/1.2098847

Yuan, J. and Sundén, B., 2006, “Analysis of Chemically Reacting Transport Phenomena in an Anode Duct of Intermediate Temperature SOFCs", ASME J. Fuel Cell Sci., Tech. and Engn., 3, 89-98. doi: $\underline{10.1115 / 1.2173662}$

Zhou, T. and Liu, H., 2004, “A 3D Model for PEM Fuel Cells Operated on Reformate", J. Power Sources, 138, 101-110. doi:10.1016/ j.jpowsour.2004.06.033 